SAND77-1164

Unlimited Release

UC-60

vind

Nor 421

\title{
Wind Turbine Data Acquisition and Analysis System
}

Bernard Stiefeld

Prepared by Sandia Laboratories, Albuquerque, New Mexico 87185

and Livermore, California 94550 for the United States Department

of Energy under Contract AT $(29-1) \cdot 789$

Printed July 1978

Sandia Laboratories 


\section{DISCLAIMER}

This report was prepared as an account of work sponsored by an agency of the United States Government. Neither the United States Government nor any agency Thereof, nor any of their employees, makes any warranty, express or implied, or assumes any legal liability or responsibility for the accuracy, completeness, or usefulness of any information, apparatus, product, or process disclosed, or represents that its use would not infringe privately owned rights. Reference herein to any specific commercial product, process, or service by trade name, trademark, manufacturer, or otherwise does not necessarily constitute or imply its endorsement, recommendation, or favoring by the United States Government or any agency thereof. The views and opinions of authors expressed herein do not necessarily state or reflect those of the United States Government or any agency thereof. 


\section{DISCLAIMER}

Portions of this document may be illegible in electronic image products. Images are produced from the best available original document. 
Issued by Sandia Laburaturies, opcrated for the IJnited States Department of Energy by Sandia Corporation.

\section{NOTICE}

This report was prepared as an accounl uf wuik sponsorod by the United States Government. Neither the United States nor the Department of Energy, nor any of their employees, nor any of their contractors, subcontractors, or their employees, makes any warranty, express or implied, or assumes any legal liability or responsibility for the accuracy, completeness or usefulness of any information, apparatus, product or process disclosed, or represents that its use would not infringe privately owned rights.

Printed in the United States of America

Available from

National Technical Information Service

U. S. Department of Commerce

5285 Port Royal Road

Springfield, VA 22161

Price: Printed Copy $\$ 4.50$; Microfiche $\$ 3.00$ 


\begin{abstract}
Under Department of Energy (DOE) sponsorship, Sandia Laboratories has implemented a program to develop verticil-dxis wind turbine (VAWT) systems. One aspert of this nrngram has heen the development of an instrumented test site adjacent to Sandia Laboratories' Technical Area I on Kirtland Air Force Base. Three VAWTs are now in operation on this test site. This paper describes the data acquisition and analyses system developed to meet the needs of the VAWT test site. The system employs a 16-bit work-length minicomputer as the major element in a stand-alone configuration. A variety of peripheral devices perform the required data acquisition functions and provide for data display and analysis. Included is a disk-based software operating system that supports a mass storagefile system, high-level language, and auxiliary software procedures.
\end{abstract}




\section{CONTENTS}

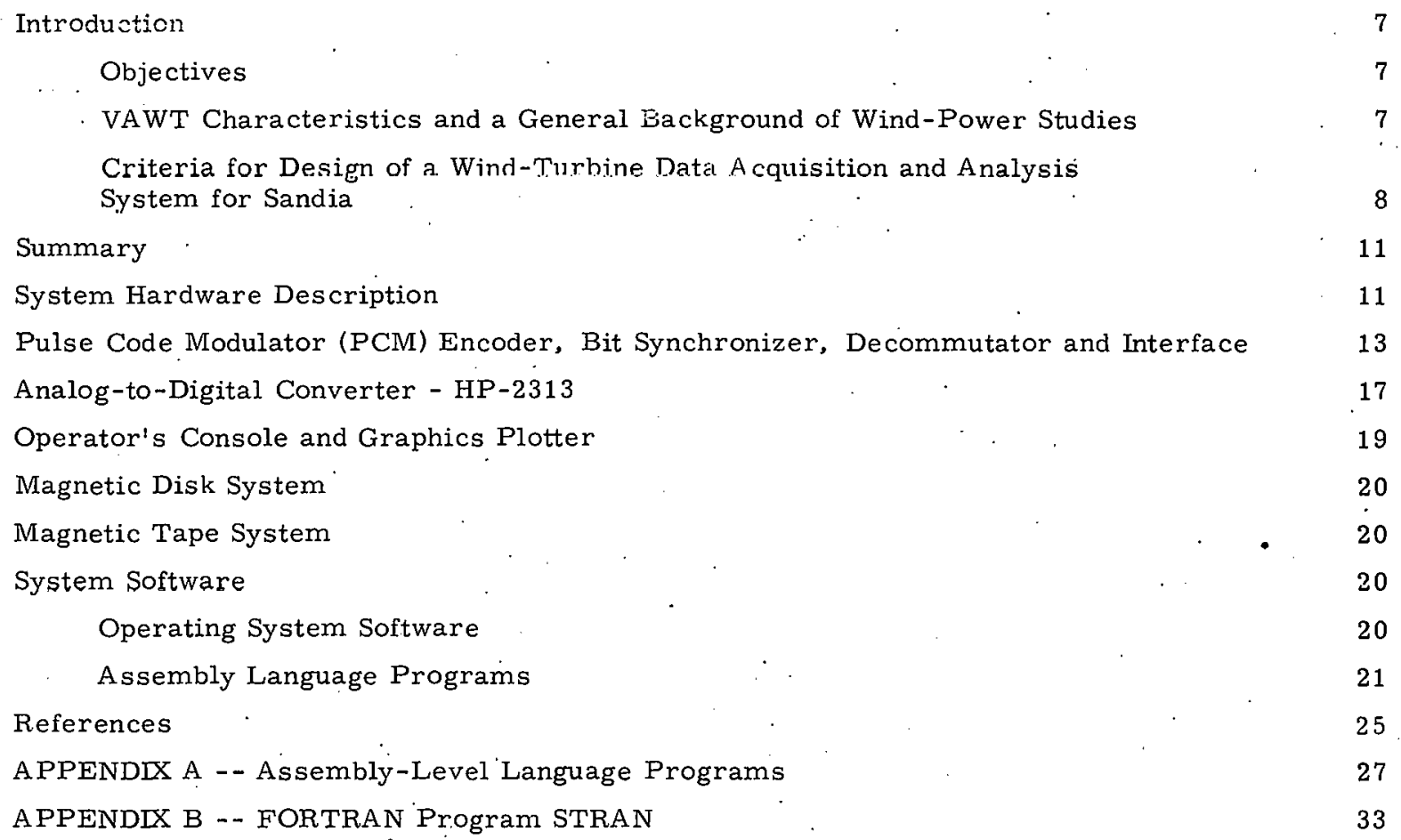

TABLES

Table

I PCM Encoder System 
WIND TURRINE DATA ACQUISITION AND ANALYSIS SYSTEM

Introduction

\section{Objectives}

The objective of this program was to develop an instrumented outdoor wind laboratory to evaluate various aspects of wind turbine performance and support general site-oriented wind studies. Instrumentation and supporting software developed for this laboratory can be applied to the evaluation of any type wind turbine or various other devices that may or may not be related to the wind program. The specific purpose of this outdoor laboratory and its instrumentation, however, is to evaluate VAWT prototype units developed as part of Sandia's wind-energy program.

\section{VAWT Characteristics and a General Background of Wind-Power Studies}

Descriptions of VAWT characteristics and a general background on the subject of wind power can be obtained by reviewing References 1, 2, and 3. At Sandia, we have erected three wind turbines: $2-\mathrm{m}, 5-\mathrm{m}$, and $17-\mathrm{m}$ machines. The $17-\mathrm{m}$ machine has been outfitted with the greatest number of transducers, and its instrumentation is described in some detail.

In evaluating the performance of the 17-m VAWT, we have concentrated on two areas:

1. Structural aspects of turbine operation, primarily blade performance, including vibratory response cliaracteristics. 4.5

3. Performaile characteristics of torque output vs wind velocity and related studies of system power losses and electrical output characteristics. ${ }^{6} 7$

Major factors considered in wind studies are determination of wind-velocity history, gustrelated frequency parameters, and terrain-related wind-shear factors. (Wind shear is evidenced by velocity difference with altitude of $\sim 0$ to $45 \mathrm{~m}$ [0 to $150 \mathrm{ft}$ ] above the surface.) This factor is important in evaluating turbine efficiency as it is applied to find the wind velocity at the turbine equator. It slivuld be noted that the power available in a moving fluid stream is proportional to the cube of the velocity; an accurate determination of wind velocity is therefore needed for calculation of performance factors. 
In designing a data acquisition system, consideration is usually given to.traditional physical parameters such as number of channels, required sampling rates, voltage levels, noisc sources, etc. However, in developing a system for use in the laboratory environment that exists at Sandia, consideration should be given to other more subtle factors. Among these are

1. background and training of principal users of the system,

2. desired end use of the data,

3. desired or required speed of data analysis- wanted and complexity of analysis,

4. propensity to modify system requirements for either hardware or software.

The ultimate usefulness and longevity of a laboratory-located system may depend its illucls on proper evaluation of these four considerations as on any traditional factors. In this instance, the users of the equipment ard data were csentially lite salle gi cup of Eandia otaff momhers. all highly trained and intimately involved with both operational and analytic phases of the Sandia windenergy program. Many of these staff members are well verșed in use of FORTRAN and time-share terminal operations, but none are familiar with detailed computer operations, and none have training at the assembly-language level. Discussions with these staff members indicated strong requirements for a flexible software and hardware system. The staff.agreed that initial operational data acquisition should use the "method of BINS"6,7 (a summary of "method of BINS" is contained in Reference 7), but much uncertainty cxisted about probable future testing after the initial cvaluations. A capability for general wind characterlstic studies was aloo decired.

Blade and cable tiedown systems tor dynamic and steady-state conditions ${ }^{4,5}$ were analyzer. Based on data from studies, we made decisions about sampling rates; blade strain-gage 10cations, and transducer/voltage response.

For technical personnel trained in their own specialties but with little experience in assembly language, computer programming, and interfacing instruments, the hardwarc/software problems can be formidable. To overcome this hurdle, the following four guides were established for procuring the control system and related instrumentation:

1. To factlitute soflware devclopmont and future snftware expansion, the system will support a high-level language, preferably one generally familiar to Sandia Laboratories personnel. An adequate file system will be available for program storage, modification, and data manipulations. The key element here is the use of a well-known, high-level lingudue. 
2. A fast multichannel analog-to-digital (A/D) converter will be the main dataacquisition unit. As a corollary to this decision, transducers and signal conditioning modules will be procured that will provide analog outputs proportional to the input stimulus. The rationale here is that the A/D converter input lines will be brought out of the colilputer system to a plug connector or strip connection system. Interfacing then involves simply wiring the analog outputs to the $A / D$ input plugs. Additions or modifications are straightforward and generally would require no modifications to the computer input-output (I/O) system. A new transducer could thus be added by personnel with little detailed computer hardware background. For software, a general-purpose A/D call from the high-level language is used so that no assembly language programming effort is required if a new transducer is added to the system.

3. To assure the quality of the data acquired and to speed up data review, the system should be capable of performing real or neär real-time data reduction and display. The term "display" here includes a reasonable graphic capability as contrasted to a minimal printing capability.

4. All elements of the computer system should come from one company, one having a good service reputation in the Albuquerque area. This requirement minimizes confusion in pinpointing responsibility when difficulties arise. Dealing with several companies to put a complex system together is almost imposibible if technical problems arise.

The major trade-off for these four items is cost. Procurement time is probably reduced because of simplifications from the user's view. Use of a high-level language generally implies supporting software items such as an editor; compiler or interpreter, file management, etc. Convenience and ease of use increases disk speed and capacity. requirements, and therefore the cost of the disk system increases over the cost of a minimal assembly-language-based system. The cost of a sultable A/D converter will be greater than that for a minimal system and additional memory to handle files and more complex data reduction programs will be required. Finally, the I/O devices to support graphic output on a fast near real-time basis will cost much more than a simple TTY device or modest speed-line printer device. 
Delivery of hardware elements of the system was made in September through November of 1976. The data system was operational at the VAWT site in January 1977, acquiring data from the 15-m VAWT that was in place. The 17-m VAWT was.installed in February and March 1977, with initial testing starting in March. The 2-m machine came into operation in March 1978.

All three machines have been interfaced with the data system with little or no deviation from the original planning. The entire system has exhibited a satisfactory level of reliability with no downtime exceeding 3 days. In approximately 18 months the data system has been down only twice. Strain-gage connections have been the principal hardware problem. Three strain gages out of 21 are now inoperable due to open leads.

Much FORTRAN-based software has now been written for the system. Generally, individual staff members have written their own programs, with at least fuur staff members having become " proficient on the system. Several general wind analysis procedures have been placed on the system, taking advantage of the ease of programming and anemometer interfacing. The graphic capability of the system has been used extensively. This has resulted in not utilizing the magnetic tape system as intended to transfer data to the Sandia central computer system.

At this time, the only significant change to the system planned is the addition of a cassette reader. This reader will read tapes from remote weather stations. Software will be developed to reduce this data to evaluate long-term site wind characteristics.

System Hordware Description

Significant elements of the data acquisition and control system are diagrammed in Figure 1. :The system Central Processing Unit (CPU), an HP 21 MX minicomputer 16-bit machine with 32, 767 words of core memory, was chosen to meet the four criteria outlined in the previous section. Sandia's facility and digital system design and development had acquired considerable software and hardware experience on a recently installed digital acquisition system. ${ }^{8,9}$ A suitable local service organization was aviailable, and several hardware/software requirements were similar to those for the proposed wind test facility and the recently completed centrifuge digital acquisition and analysis system. 


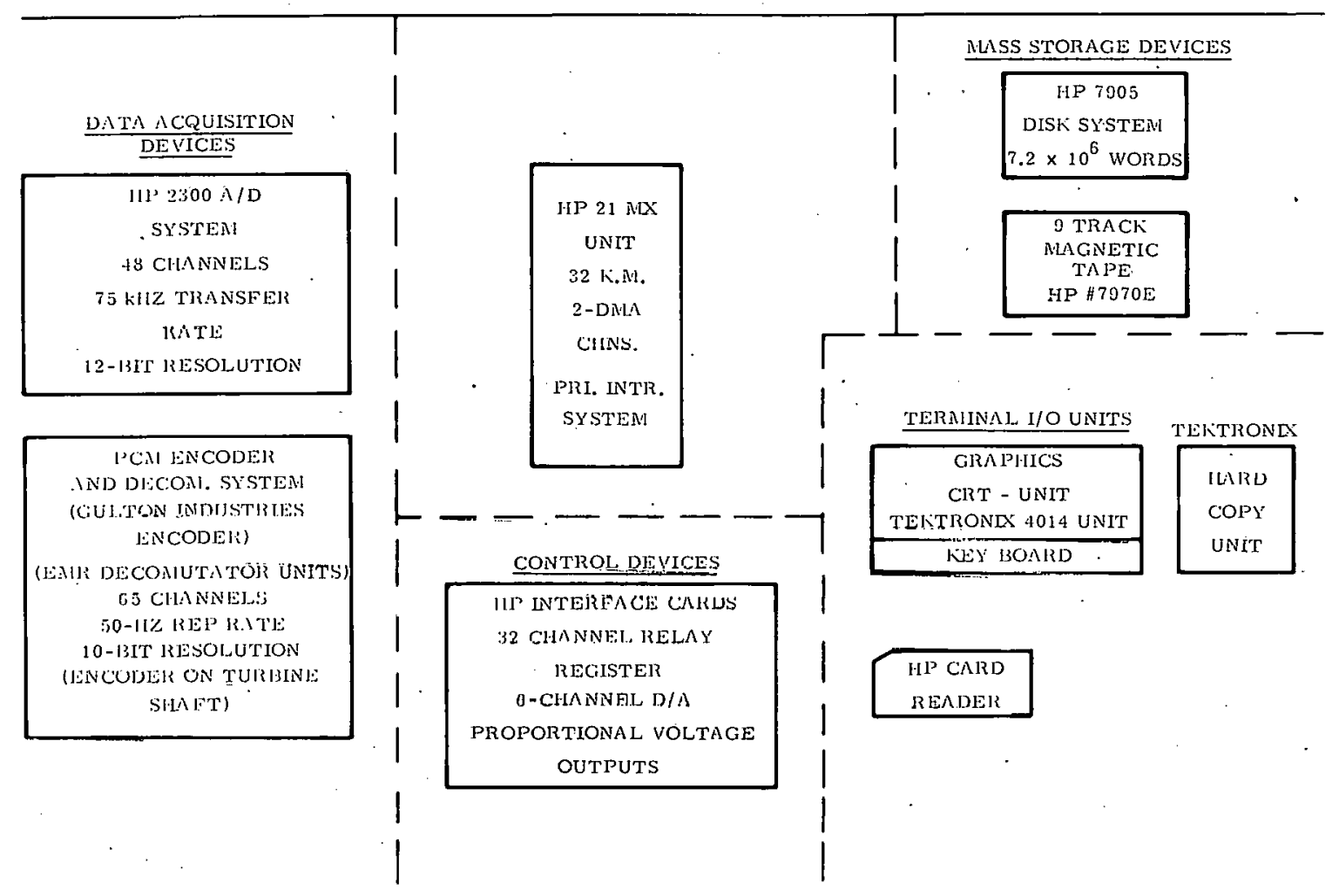

Firure 1. HP 21 IVX Computer System Elements

For ease of interfacing and system software utilization, the following items were sole-sourced from the CPU manufacturer at the same time the CPU order was placed.

1. HP 2313 A/D system with 48 channels

2. HP multiprogrämmer urilt

3. HP 79057.2 megaword disk system

4. HP 7970E 9-track high-density magnetic tape system

5. HP relay interface card

6. HP papcr tape reader

7. HP card readcr

All equipment is mounted in a standard 6 - $\mathrm{ft}$ tall, double-bay instrument rack. Items $3,4,6$, and 7 ahove deal only with the CPU unit. Their service maintenance is a problem for the HP service organization. Items 1, 2, and 5 deal with data signals from the turbines, but it is easy to determlue if the turbine signals are present and, if so, whether malfunctions are HP service problems. It is important that the wind group's few instrument people do not spend excessive time dealing. with the complcx CPU/peripheral interfaces. After initial shakedown, this equipment has been reliable, with little down time. The Tektronix graphics termirlal and its hard-copy unit were procured hecause of relative simplicity in use, availability of software support at Sandia, and lack of competitive options during procurement.

The following information describes specifications for the significant system components. 
Pulse Code Modulator (PCM) Encoder, Bit Synchronizer, Decomimutator and Interface

The major task of the PCM system is to provide a noise-free way to acquire high- and lowlevel data from the rotating members of the turbine. Figure 2 is a system diagram of the encoder system. Basically, the encoder takes multiple analog data channels and converts from analog form to a serial digital data stream, adding frame-sequence and word-sequence coding. The bit synchronizer and decommutator located in Building 899 near the CPU decode the serial stream, provide frame pulses, and parallel digital data words to the computer interface unit for acquisition by the computer as determined by appropriate programs. The advantage of the PCM system is that multiple channels (65 in our case) of data are compressed into a single transmission channel containing high-level digital data. This high-level digital stream is largely immune to the usual analog AM noise encountered in slip-ring operation and cable transmission.

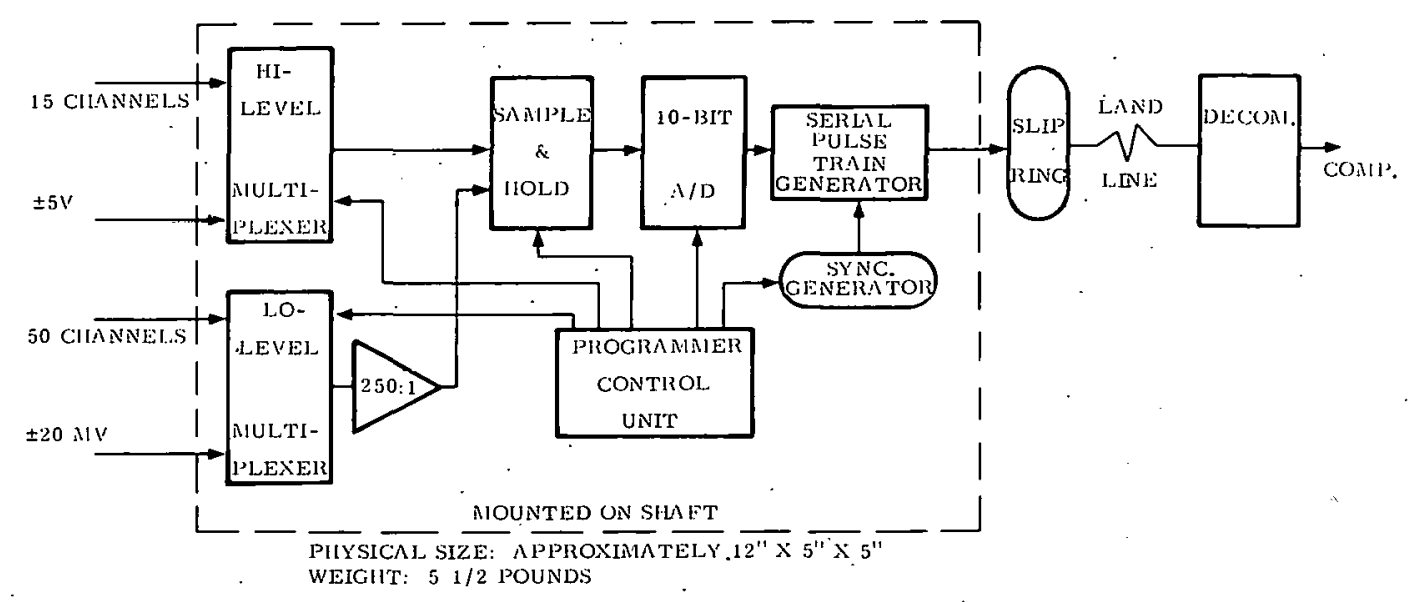

Figure 2. PCM Encoder System Diagram

PCM systems typically operate in a continuous-frame-oriented mode, which requires computer memory space for an integer number of frames. In our case, since only about 30 of the 65 data words in a frame are used (to allow for expansion), much memory space would be wasted. To overcome this jiublem, the Sandia-designed interface between the PCiM decommutator and computer passes only à program-specified group of continuous data words from éach frame. This hardware/software match maximizes the number of memory words avallable for data taken with the PCM system. To aid in implementing this feature, high- and low-level channels are intermingled in the data-word sequence so that a continuous group of data words can be set up. Table I details the parameters of the PCM encoder system. The data-word sequence of 65 words (2 sync words are not included) is outlined in Table I, along with the connector designations. We are now using data words 16 to 46 , which give a continuous combination of high- and low-level channels. 


\section{S - SYNC DATA. WORDS}

Two Sync Words (S1 and S2) Per Frame

INSB

S1- $\quad \begin{array}{lllllllllll}1 & 0 & 1 & 0 & 1 & 1 & 0 & 1.0 & 0 & 1\end{array}$

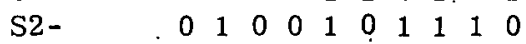

A - ANALOG DATA WORDS

Fifteen Analog Wörds. H1-Level Differenlial Bipulai

$\pm 5.115 \mathrm{~V}$ Full Scale @ 10.0.MV/Bit

Accuracy: $\pm 0.2 \% \pm 1 / 2 \mathrm{LSB}$

$\pm 15.22 \cdot \mathrm{MV}^{\mathrm{T}} \mathrm{U} \perp 21 / 2 \mathrm{LGB}$.

\section{B - ANALOG̈ DATA WORDS}

Eighteen Analog Words, Low-Level Differential Bipolar w/o Filter $\pm 20.46 \mathrm{MV}$ Full Scale (a) 40.0 MV/Bit

Accuracy: $\pm 2.2 \% \pm 1 / 2 \mathrm{LSB} \operatorname{Max} \pm 1.5 \% @ 25^{\circ} \mathrm{C}$

$\pm 0.470 \mathrm{MV}$ or $\pm 12 \mathrm{LSB}$

\section{C - ANALOG DATA.WUKLS}

Thirty-two Analog Words. Low-Level Differential Bipolar With Filter $\pm 20.46 \mathrm{MV}$ Full Scale @ 40.0 MV/Bit

A cciuracy: $\pm 2.2 \% \pm 1 / 2 \mathrm{LSB} \pm 1.5 \% @ 25^{\circ} \mathrm{C}$ $\pm 0.470 \mathrm{MV}$ or $\pm 12 \mathrm{LSB}$

Filter: $3 \mathrm{db} @ 25 \mathrm{~Hz}$ Max $6 \mathrm{~dB}$ Her Uctave Rolloff

EXCITATION VOLTAGE

Sixty Channels@10 Volts \pm 5 IMV into a.350-Ohm Bridge

\section{FRAME STRUCTURE}

Bit Rate: $33.5 \mathrm{kHz} \pm 1 \%$

Word Rate: $3.35 \mathrm{kHz} \pm 1 \%$ (10 Bits Per Word)

Frame Rate: $50 \mathrm{~Hz} \pm 1 \%$ ( 67 Words Per H'rame)

'l'emperature Range: $-20^{\circ} \mathrm{C}$ lu $+80^{\circ} \mathrm{C}$

ITL DIGITAL OUTPUTS

1. Biplıase L, MEB First Out Difforontial Line Driver 7830

2. Frame Rate Strobe, One TTL Lcad Drive

3. Bit Rate Clock, One TTL Load Lrive

\section{ADC OUTPUT CODES}

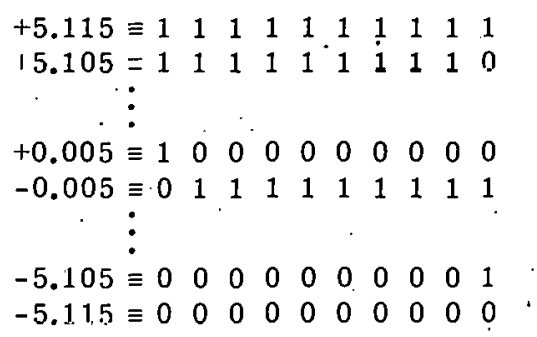


TABLE I (cont)

ENCODER POWER CONNECTOR J1

$\begin{array}{ll}\text { PIN } & \text { FUNCTION } \\ 1 & +28 \mathrm{~V} \\ 2 & +28 \mathrm{~V} \\ 3 & \text { Case Gnd. } \\ 4 & -28 \mathrm{~V} \text { Return } \\ 5 & -28 \mathrm{~V} \text { Return }\end{array}$

$\begin{array}{ll}\text { PIN } & \frac{\text { FUNCTION }}{1} \\ 2 & +28 \mathrm{~V} \\ 3 & +28 \mathrm{~V} \\ 4 & \text { Case Gnd. } \\ 5 & -28 \mathrm{~V} \\ & -28 \mathrm{~V} .\end{array}$

\section{ENCODER OUTPUT CONNECTOR J2}

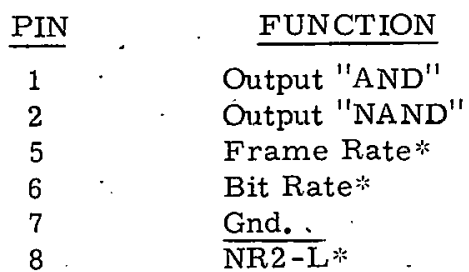

*Test points only

NOTE: Output taken. between Pins 1 and 7

Analog Input Channels

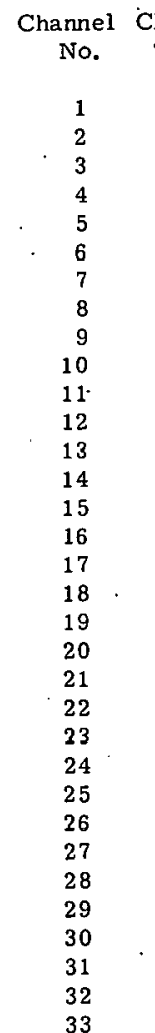

Channel Connector

'lype* and Pins : Function

A1 - J3-62,61 Unassigned

A2 J3-10,9 Unassigned

A3 J3-36, 35 Unassigned

A4 J3-60,59 Unassigned

A5 J3-56,55 Unassigned

B1 J4-62,61 Unassigned

B2 J4-10,9 Unassigned

B3 J4-36,35 Unassigned

B4 J4-60,59 Unassigned

B5 J4-56,55 Unassigned

B6 J4-4,3 Unassigned

B7 J4-6, 5 Unassigned

Do j4-ju, 2y Undssilguted

B9 J4-38, 37 Unassigned

B10 J4-14,13 Unassigned

C1 J5-62,61 Strain Gage 104

C2 J5-10,9 Strain Gage 105

C3 J5-36, 35 Strain Gage 101

C4 J5-60,59 Strain Gage 102

C5 J5-56,55 Straịn Gage 103

C6 J5-4,3 Strain Gage 106

C7 J5-6, 5 Strain Gage 107

C8 J6 30,20 Elivin Qdye 108

C9 J5-38,37 Strain Gage 109

C10 · J5-14,13 Strain Gage 110

C11. J6-13,11 Etrain Gagé 111

C12 J5-61,63 Strain Gage 112

$\mathrm{C} 13 \mathrm{~J} 5-34,33$ Strain Gage 113

C14 J5-58,57 Strain Gage .114

C15 J5-8,7 Unassigned

C16 J5-32,31 Unassigned

A6 J3-4, 3 Flex, Displ. Gage

A 7 J3-6, $17 \mathrm{M}-$ W.V.
Channel Connector

Type* and Pins

A 8 J3-30,29 17 M-W.D.

A9 J3-38,37 Torque-Main Shft.

A10 J3-14,13 Torque-Motor Shft

B11 J4-12,11 Strain Gage 104

B12 J4-64,63 Strain Gage 105

B13 J4-34, 93 Strain Gage 113

B14. J4-58,57 Strain Gage 114

C17 J5-46,45 Strain Gage 115

C18 J5-22,21 Strain Gage 116

C19 J5-20,19 Strain Gage 117

C20 J5-72,71 Strain Gage 303

C21 J5-42,41 Strain Gage 304

C22 $J 5-66,65$ Strain Gage 301

C23 J5-16,15 Strain Gage 302

C24 J5-40,39 Unassigned

C25 J5-24,25 Unassigned

C26 J5-48,47 Unassigned

C27 J5-50,49 Unassigned

C28 J5-74,73 Unassigned

C29 J5-18,17 Unassigned

C30 J5-70,69 Unassigned

C31 J5-68,67 Unassigned

-32 J5-44,43 Unassigned

A11 J3-12,11 Unassigned

A12 J3-64,65 Unassigned

A13 J3-34,33 Unassigned

A14 J3-58,57 Unassigned

A15 J3-8,7 Unassigned

B15 J4-8, 7 Unassigned

B16 J4-32, 31 Unassigned

B17 J4-46,45 Unassigned

B18 J4-22, 21 Unassigned

*Type A rhns \pm 5.1.1.5V Fullscalo

Type B Chns $\pm 20.46 \mathrm{MV}$ Fullscale w/ 0 filters

Type C Chns $\pm 20.46 \mathrm{MV}$ Fullscale $w / 25 \mathrm{H} 2$ Low Pass filter 
TABLE I (cont)

PCM Excitation Voltage Channels (60- $\pm 10 \mathrm{~V}-$ Shunt Regulated Channels)

(Grouped in Units of 12)

J6-Connector

\begin{tabular}{|c|c|}
\hline $\begin{array}{l}\text { Pwr Supply } \\
\text { Channel No. }\end{array}$ & $\begin{array}{c}\text { Conn. Pins } \\
+,-\end{array}$ \\
\hline 49 & 28,29 \\
\hline 50 & 30,31 \\
\hline 51 & 32,33 \\
\hline .92 & 31,35 \\
\hline 53 & 36,37 \\
\hline 54 & 38,39 \\
\hline 55 & 411,41 \\
\hline 56. & 42,43 \\
\hline 57 & 44,45 \\
\hline 58 & $46,47^{\circ}$ \\
\hline 59 & 48,49 \\
\hline 60 & 50,51 \\
\hline $\begin{array}{c}\text { On/Off } \\
49-60\end{array}$ & 53,52 \\
\hline 37 & 54,55 \\
\hline 38 & 56,57 \\
\hline 39 & 58,59 \\
\hline 40 & 60,61 \\
\hline 41 & 62,63 \\
\hline 42 & 64,65 \\
\hline 43 & 66,67 \\
\hline 44 & 68,69 \\
\hline 45 & 70,11 \\
\hline 46 & 72,73 \\
\hline 47 & $74, \quad 75$ \\
\hline .48 & 76,77 \\
\hline $\begin{array}{c}\text { On/Off } \\
37-40\end{array}$ & 79,78 \\
\hline
\end{tabular}

J7-Connector

\begin{tabular}{|c|c|}
\hline $\begin{array}{l}\text { Pwr Supply } \\
\text { Channel No. }\end{array}$ & $\begin{array}{c}\text { Conn. Pins } \\
t,-\end{array}$ \\
\hline 25 & 2,3 \\
\hline 26 & 4,5 \\
\hline 27 . & 6,7 \\
\hline 28 & 8,9 \\
\hline 29 & 10,11 \\
\hline 30 & 12,13 \\
\hline 31 & 14,15 \\
\hline 32 & 16,17 \\
\hline 33 & 18,19 \\
\hline $34 \quad-$ & 20,81 \\
\hline 35 & 22,23 \\
\hline 36 & 24,25 \\
\hline $\begin{array}{c}\text { On/Off } \\
25-36\end{array}$ & 27,26 \\
\hline 13 & 28,29 \\
\hline 14 & 30,31 \\
\hline 15 & 32,33 \\
\hline 16 & 34,35 \\
\hline 17 & 36,37 \\
\hline 10 & 38,39 \\
\hline 19 & 40,41 \\
\hline 20 & 42,43 \\
\hline 21 & 44,15 \\
\hline 22 & 46,47 \\
\hline 23 & 48,49 \\
\hline 24 & 50,51 \\
\hline $\begin{array}{c}\text { On/Off } \\
13-24\end{array}$ & 53,52 \\
\hline
\end{tabular}

J7-Connector

\begin{tabular}{|c|c|}
\hline $\begin{array}{c}\text { Pwr Supply } \\
\text { Cliannel No. }\end{array}$ & $\begin{array}{c}\text { Conn. Pins } \\
+,-\end{array}$ \\
\hline 1 & 54,55 \\
2 & 56,57 \\
3 & 58,59 \\
4 & 60,61 \\
5 & 62,63 \\
6 & 64,65 \\
7 & 66,67 \\
8 & 68,69 \\
9 & 70,71 \\
$10 .-$ & 72.73 \\
11 & 74,75 \\
12 & 76,77 \\
\hline On/Off & \\
$1-12$ & 79,80 \\
\hline
\end{tabular}

Another subtlis feature of the frame-oriented data sequencing that is useful from a software point of view, is the time segregation effect of framing. At the $50-\mathrm{Hz}$ frame rate, we can consider all the data in one frame as being at the same time point. It is oflell important to investigate the time relationship between parameters. Very simple softwarc approachus wa lis usad to plot data which is already time-segregated because of the framing action of the PCM encoder. For this reason, high-level analog signals representing wind velocity, wind direction, and torque outputs are passed from the ground through the slip-ring assembly to the PCM encoder.

Strain gages positioned on the blades are designated by a three-digit number, ${ }^{10}$ the most significant digit indicating the blade and the lesser digits the gage. One additional feature of this PCM encoder unit is the provision for strain-gage excitation voltage. From the initial planning 
stages, it has been assumed that the principal transducers employed on the rotating elements of the VAWT would be strain gages. To accommodate this situation, the box containing the PCM encoder also includes $6010-\mathrm{V}$, shunt-regulated excitation channels. These channels are physically contained on five printed circuit cards so that any group of 12 excitation channels can be independently turned on or off. Each channel is self-regulating and is therefore independent of possible faults on any other gage channel. The one restriction typical of shunt regulation units is that if a completely open circuit occurs, the regulator circuits demand more current than the power supply can furnish. This has not been a problem; however, if any group of 12 channels are turned on, a 350-ohm load should be placed across any channels not connected to a gage.

Table I includes the PCM encoder connectors indicating pin designations, PCM channel number, functional use, and general parameters of the encoder. It should be noted that the framing rate is programmed at $50 \mathrm{~Hz}$. This implies that $25 \mathrm{~Hz}$ is the maximum frequency that should be digitized. This limitation may be overcome by reprogramming the encoder control unit or (in a limited case) connecting the signal in parallel to two evenly spaced channels to give a greater sampling rate to the signal, a form of supercommutation.

Analog-to-Digital Converter - HP-2313

This is the major data input device for the system. The A/D converter is presently equipped with a programmable pacer, 32 channels of high-level, and 16 channels of low-level programmable gain (seven gain steps giving a range between $\pm 5 \mathrm{MV}$ and $\pm 1.25 \mathrm{~V}$ ). All channels are differentially connected to suppress noise. Four empty card slots are available for expansion of up to 64 additional channels.

The HP-2313 can be used in either a random or sequential channel access mode. For application flexibility, we have employed the unit only in the random access mode. In this mode, and including software conversion times, the average reading speed is $\sim 150$ microseconds per channel requested. The high-level channels have a voltage range of $\pm 10.24 \mathrm{~V}$, with a 12 -bit 2 's complement binary word output. Voltage resolution is $\sim 5 \mathrm{MV}$ per bit.

The programmable pacer controls the sampling rate at which readings are taken. This can be done under program control using the computer interrupt system. The range of sample rates can be varied from one sample every 2550 seconds to 45,000 samples/s. This sample rate is programmed as a product of a variable microsecond time base between 0 and 255 and an integer power of 10 between 0 and 7 .

To make it easier to connect signals to the A/D unit, maintain flexibility, and allow untrained personnel to use the system, all A/D channels are precabled to a connector bank mounted outside the computer enclosure. Connecting a new signal source then involves only mating to the appropriate ' pins of the connector. It is not necessary to go into the HP 2313 and manipulate internal connectors. 
With this approach, modifications can be made to the experiments without risking damage to the A/D converter unit. Table II lists the connector pin and functions for the connectors mounted on the back of the computer rack.

\section{TABLE II}

Connector Designations for Cómputer Rack-Mounted Devices

\section{AN-Connector No. 1}

\section{Pins Used}
A, R
C, D
$\mathrm{E}, \mathrm{F}$
G. $\mathrm{H}$
J, K
I., $M$
N, $P$
$R, S$
T, .U
$\mathrm{V}, \mathrm{W}$
$\mathrm{X}, \mathrm{Y}$
Z, a
$b, c$
d, e
f, $g$
$h, i$
$j, k$
$\mathrm{m}, \mathrm{n}$
$p, g$
$r, s$
$t ; u$

\section{Computer Device}

A / D Chn 13

A/D Chn 14

A/D Chn 15

A/D Chn 16

A / D Chn 17

A / D Chn 18

A /D Chn 19

A/D Chn 20

A. / Chn 21

A/D Chn 22

Relay Chn 10

Relay Chn 11

Relay Chn 12

Relay Chn 13

Relay Chn 14

Relay Chn 15

Relay Chn 16

Relay Chn 17

Relay Clun 18

Relay Chn 19

Relay Chn 20

\section{Functional Application}

17/M Hi-Level Torque

17/M Lo-Level Torque

$17 / M$ Upper Shaft RPM

17/M Motor Shaft RPIVI

$17 / \mathrm{M} 100^{\prime}$ Wind Velocity

$17 / \mathrm{M} 80^{\prime}$ Wind Velocity

$17 /$ M 100' Wind Direction

5/M Torque Output

$5 / \mathrm{MI}$ Fence Wind Velocity.

$5 / \mathrm{M}$ Centerline Wind Velocity

Unassigned

\section{AN-Connector No. 2}

$\underline{\text { Pins Used }}$

A, B

$r: n$

E, F

G, $\mathrm{H}$

$I, K$.

L. M

N, P

$\mathrm{R}, \mathrm{S}$

T, TI.

$\mathrm{V}, \mathrm{W}$

$\mathrm{X}, \mathrm{Y}$

Z, d

b, c

d, e

r, g

$h, i$

j, k

$m, n$

$p, q$

$r, s$

$t, u$

$v, w$
Computer Device

A/D Chn 23

A/D Chn 24

A/1) ('hn 25

A/D Chn 26

A. / D Chn 27

A/D Chn 28

A/D Chn 29

A / D Cinn 30

$\Lambda / \mathrm{D}$ Chn 31

A / D Chn 32

Relay Chn 21

Relay Chn 22

Relay Chn 23

Relay Chn 24

Relay Chir 25

Relay Chn 26

Relay Chn 27

Relay Chn 28

Relay Chn 29

Relay Chn 30

Relay Chn 31

Relay Chn 32
Functional Application

Tower 12' Velocity

'l'ower 34' Velocity

Tower 58' Velocity

Tower IUU' Velocity

Tower 12 Direction

Tuwer 34' Direction

Tower $58^{\prime}$ Direction

Tuwer' $100^{\prime}$ Direcilion

2.M Wind Vel.

$2 \mathrm{M}$ Wind Dir 
Jones Strip Block

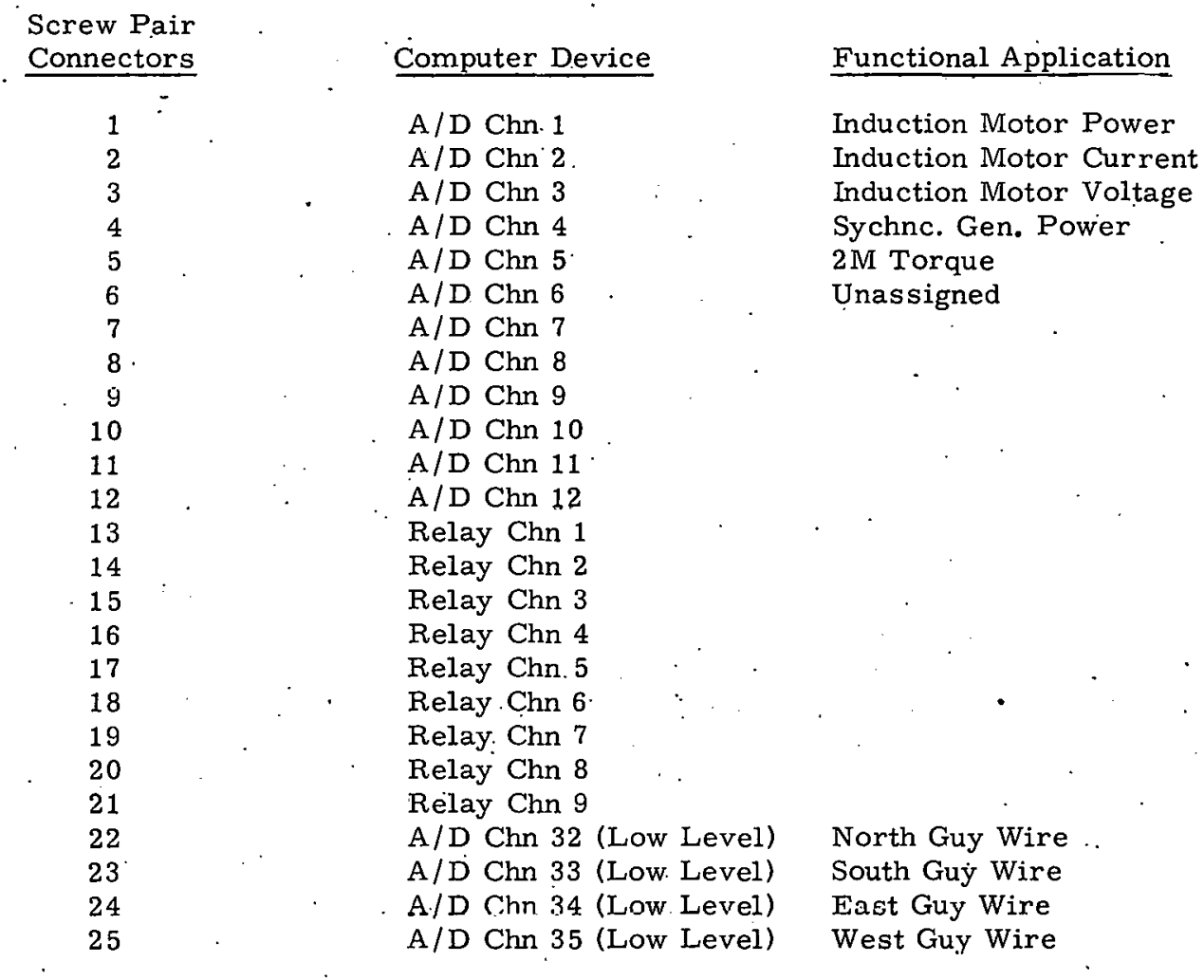

'Operator's Console and Graphics Plotter'

The operator's console is a Tektronix 4014-1 CRT terminal with a mating Tektronix 4631 hardcopy unit. This terminal is a memory scope/keyboard combination that allows for alpha and graphic mode operations. We have provided no other listing device with this system:

In the alpha mode the terminal provides interactive keyboard capability with a 9600-baud output rate. When placed in the graphics mode, the terminal can be used as a high-speed, high-resolution plotter (1024 horizontal points, 780 vertical-axis points):

The 4631 hardcopy unit provides acceptable report-quality copies of the sciren contents. Used with the automatic copy command features, the terminal/hardcopy pair can be a moderatespeed listing device or graphic output unit. Tektronix-furnished plotting software has been modified by Sandia Laboratories to provide a hardware/software plotting capability for this system. ${ }^{9}$ A key element in the successful use of this system has been the flexibility provided by the terminal/ hardcopy.pair. 
Magnetic Disk System

The system disk is an HP-7905 moving hedd disk containing one fixcd and one removable disk platter. The two surfaces of the removable-disk platter provide a maximum storage capability of 5 million 16-bit words. Only one surface of the fixed platter can be used for storage (the second surface is used for disk control features), providing 2.5 miliion words. Total active storage for the disk then is 7.5 million 16 -bit words. With appropriate program techniques and interchanging removable platters, an "infinite" total storage can be achieved.

renerally. the fixed-disk platter is the depository for the system operating software, while the removable platter acts as the data storage area. But it should be understood that the operating software has equal access to all disk süriaces. Progr'dus dul dala vall he stored and a.oooodod from appropriately named files located on any surface under program control.

\section{Magnetic.Tape System}

The second mass storage system is an HP-7970E magnetic tape system. This tape system, a 1600-bpi, 45-ips, nine-track, phase-encoded unit, is compatible.with tapc drives generally found on large central computing facilities. The major reason for procuring the tape system was to provide a convenient way to transfer data between our minicomputer system and other large-scale systems. This option has not been used primarily because of the graphic and analytic capabilities of the minicomputer; there has been no incentive to go to the large-scale systems.

\section{System Software}

\section{Dperating System Software}

The software operating system chosen for the syistem was HP's DOS III. DUS III supports the following:

1. FORTRAN IV compiler.

2. File text editor

3. Named file system. 


\section{Assembler}

5. Interrupt and direct memory access (DMA) operations

6. Relocatable loader (capable of loading FORTRAN and assembly-level subroutines)

Although reasonably powerful, the DOS III allows only 24, 000 memory words for the operating user program area. Considering the power of the operating system, this is a very large program area.

The major disadvantages of the DOS III system are its lack of time-oriented tasking function's and the slowness of the compiler and assembler.

A nonstandard FORTRAN feature under DOS known as the "executive," allows FORTRAN programs access to all peripheral devices and the named files. The executive call is a FORTRAN statement resembling the usual subroutine call format. Arguments provided for in the call format specify the operation desired, logical unit involved (if any), file name, number of data words, and relative starting location of data transfer. When executed in an operating program, this executive call uses available monitor routines to perform the specified functions. A programmer familiar with standard FORTRAN subroutine operations can quickly use this feature to access the file system or DMA-type transfers.

\section{Assembly Language Programs}

As described above, the executive-call feature provides access to the standard data-handling peripherals (the PCM system interface is designed to have DMA to the system and is controlled then by a variation of the executive call). The A/D converter, relay units and digital-to-analog (D/A) units do not fit under the executive format.

To forestall the need for programmers to write difficult assembly-language routines for these units in each application program, five general-purpose assembly language subroutines are provided. These subroutines may be loaded with a main FORTRAN program and executed by using standard FORTRAN call statements. Arguments are provided to ensure much flexibility in the use of the subroutines. Where appropriate, the arguments are keyed to hardware features of the devices. Under this approach FORTRAN-oriented programmers have full command over all features of the system.

The following are argument descriptions for each call. Appendix A lists each assemblylanguage routine. Note that the program PADC includes two entry calls, GAIN and PADC. 
1. Form of FORTRAN call

CALL GAIN (N)

This call varies the gain of the low-level A/D channels. The argument $\mathrm{N}$ can be an integer constant or variable name between 1 and 7 . Resulting gains are

$$
\begin{aligned}
& 0=1000 . \quad 4=100 \\
& 1=500 \quad 5=50 \\
& 2=250 \quad 0=25 \\
& 3=125 \quad 7=12.5
\end{aligned}
$$

The GAIN call sets A / D channels 33 to 48 to the specified gain. If GAIN is not called in the program, a default gain of 500 is in effect.

2. Form of FORTRAN call

Cali PADC (N, ICH, V, IPER, IBASE, IST, NAM)

$N$ - IVlay be a constant or integer variable; it defines the number of channels to be read.

ICH - Name of a previously defined array. Array locations from ICH(1) to ICH(N) must be assigned the appropriate channel numbers to be read. Channel number may be in any sequence.

$\mathrm{V}$ - The name of a previously defined floating point array. The floating point voltage results are returned in this array in the sequence in which they are read.

IPER, IBASE - May be integer constants or variables. These two arguments control the sampling rate at which the $A / D$ unit will operate. IPER must have a value between 0 and 255; this number is a microsecond factor. IBASE must have a value between 0 and 7 and is considered a power-of -10 exponent. IPER equal 1 and IBASE equal 6 specifies a 1 -s period. IPER equal 5, IBASE equal 6 epecifies a sampling period of $0.5 \mathrm{~s}$. If $I P L R$ and $L B A S E$ equal 0 , no interrupts will occur; only the first set of readings will be taken.

IST - Must be an integer variable name; it must not be an integer constant. IST is employed as a flag for the system. Generally IST is preset to zero (0) prior to making the IST PADC call. Each time the system takes a set of readings, the software will increase IST by $N$. This allows one to build a logic loop checking the value of IST to determine if a new set of readings has been taken. If IST is set to a negative value when called, the system will use the optional subroutine argument during each interrupt sequence.

NAM - Must be the name of a subroutine compiled with the main FORTRAN program; the subroutine must contain two arguments $N, V$. If IST is set negative on the first call, each interrupt sequence will jump to this subroutine setting the correct values for $\mathrm{N}$ and $\mathrm{V}$ : This feature allows a FORTRAN programmer to accumulate. data at a specified interrupt sampling rate while his main program performs other duties. This feature. is optional, and the argument NAM may be omitted; if omitted, care must be taken to ensure that IST is not negative when the PADC call is made. 


\section{CAUTION}

In all cases where PADC is used, a call to PADC should be made with IPER and IBASE equal 0 before the program is terminated. Failure to do this will cause system.monitor errors, as the $\mathrm{A} / \mathrm{D}$ converter will continue to cause interrupts to a memory area that may be used by the monitor after program termination.

\section{RELAY CONTROL CALL.}

CALL RELAY ( $N$, ICH)

N - Number of relays affected by the call. Argument may be either an integer constant or variable.

ICH - A predimensioned integer array. Values of $\mathrm{ICH}(1)$ to $\mathrm{ICH}(\mathrm{N})$ must be assigned arguments representing relay channel numbers. A positive argument will cause the relay to close its normally open contact; a negative argument will open the contact. After a call to RELAY, all relays maintan their settings until the next call.

DIGITAL-TO-ANALOG CONVERTER CALL

CALL DAC (N, ICH, V):

This call is used to obtain program-controlled analog voltages. A voltage range of $\pm 10 \mathrm{~V}$ is obtainable with a 5-MV resolution.

N - May be either an integer variable or constant.

ICH - Must be a predimensioned integer array. The locations ICH(1) to ICH(N) must be assigned values corresponding to the DAC channels to be modified.

$\mathrm{V}$ - Must be a predimensioned real array. The locations $\mathrm{V}(1)$ to $\mathrm{V}(\mathrm{N})$ must be aEeignod valuoo correoponding to the voltageo desircd on the corresponding DAC channels.

Appendix $\mathrm{C}$ lists the assembly-level programs used to implement these calls.

\section{FORTRAN Examples}

Tn illustrate the use of a call in a FORTRAN program, the following program demonstrates the use of PADC. The program reads A/D channels 5, 3 and 4 , reading the three channels every $0.25 \mathrm{~s}$. Ten readings are stored in an array group.

C - The dimension statement establishes necessary FORTRAN array spaces. DIMENSION ICH(10), V(10), STOR1(10), STOR2(10), STOR3(10).

$\mathrm{C}$ - The following statements set number of channels to be read,

$C$ - assigns channel numbers, sets the sampling period of 0.25

$\mathrm{C}-\mathrm{s}$ and finally initializes the flag word IST. 


$$
\begin{aligned}
& N=3 \\
& \operatorname{ICH}(1)=5 \\
& \operatorname{ICH}(2)=3 \\
& \operatorname{ICH}(3)=4 \\
& \operatorname{IPER}=25 \\
& \operatorname{IBASE}=4 \\
& \text { IST }=0
\end{aligned}
$$

C - The variable IGOUNT is used to count the number of readings

C - (interrupt sequences).

ICOUNT $=0$

C - The following two lines calls PADC turning on the A/D

$\mathrm{C}$ - unit and set in a.s a comparison value to check for when

C - interrupts have occurred.

CAILI, PADC (N. ICH. V. IPER, IBASE, IST)

IN $=$ IST

C - The following single line loop waits for interrupts to modify IST.

10 (IN . EQ . IST) GO TO 10

C - The following lines modify IN to match the new value of

C - IST, stores voltage readings into their permanent place

$\mathrm{C}$ - and checks the number of interrupts to determine if the pro-

C - gram should terminate.

$$
\begin{aligned}
& \text { IN }=\text { IST } \\
& \text { NI }=\mathrm{NI}+1 \\
& \operatorname{STOR} 1(\mathrm{NI})=\mathrm{V}(1) \\
& \operatorname{3TOR2}(\mathrm{NII})-\mathrm{V}(2) \\
& \text { STOR3(NI) }=\mathrm{V}(3) \\
& \text { IF }(\mathrm{NI} \cdot \mathrm{EQ} \cdot 10) \text { GO TO } 20 \\
& \text { GO TO } 10
\end{aligned}
$$

C - The final line causes the A/D unit to halt its interrupt

$\dot{C}$ - processes by calling PADC again with $\phi$ arguments in the

C IPER, IB $\Lambda$ SE poditiono.

$20 \mathrm{CALL}$ PADC (N, ICH, V, $\emptyset, \phi$, IST)

STOP

Appendix $B$ is a listing of a FORTRAN program to acquire data from specified PCM channels and automatically plot the data in limits of microstrain vs time in seconds. A review of this program will show that it is almost indistinguishable from a FORTRAN program used on large-scale machines to perform similar scaling and plotting operations. 
1. P. C. Putnam, Power from the Wind, VNR Company, 1948.

2. B. F. Blackwell and L. V. Feltz, Wind Energy - A Revitalized Pursuit, SAND75-0166, Sandia Laboratories, Albuquerque, NM, April 1974 (reprinted December 1974).

3. B. F. Blackwell, The Vertical-Axis Wind Turbine "How It Works, " SAND74-0160, Sandia Laboratories, Albuquerque, NM, April 1974 (reprinted December 1974).

4. L. N. Weingarten and R. E. Nickell, Nonlinear Stress Analysis of Vertical-Axis Wind Turbine -Blades, SAND74-0378, Sandia Laboratories, Albuquerque, NM, April 1975.

5. R. C. Reuter, Jr., Tie-Down Cable Selection and Initial Tensioning for the Sandia 17-Meter Vertical-Axis Wind Turbine, SAND76-0616, Sandia Laboratories, Albuquerque, NM February 1977.

6. J. F. Banas, E. G. Kadlec, and W. N. Sullivan, Methods for Performance Evaluation of . Synchronous Power Systems Utilizing the Darrieus Vertical-Axis Wind Turbine, SAND75-0204, Sandia Laboratories, Albuquerque, NM, April 1975.

7. R. E. Akins, Performance Evaluation of Wind Energy Conversion Systems Using the Method of Bins - Current Status, SAND77-1375, Sandia Laboratories, Albuquerque, NM, March 1978.

8. R. N. Tomlinson, Plotting on the Tektronix 4010, 4012, and 4014 Terminals from HewlettPackard DOS/RTE Operating Systems Using Modified Tektronix Plot-10 Software, SAND771513, Sandia Laboratories, Albuquerque, NM, January. 1978.

9. R. N. Tomlinson, Digital Data Acquisition and Analysis System for the 8.8 and 10.7 Meter Centrifuge Facilities System Capabilities Report, SAND77-1502, Sandia Laboratories, Albuquerque, NM, January 1978.

10. W. N. Sullivan, Preliminary Blade Strain Gage Data on the Sandia 17-Meter Vertical-Axis Wind Turbine, SAND77-1176, Sandia Laboratories, Albuquerque, NM, December 1977. 
APPENDIX A

Assembly-Level Language Programs 


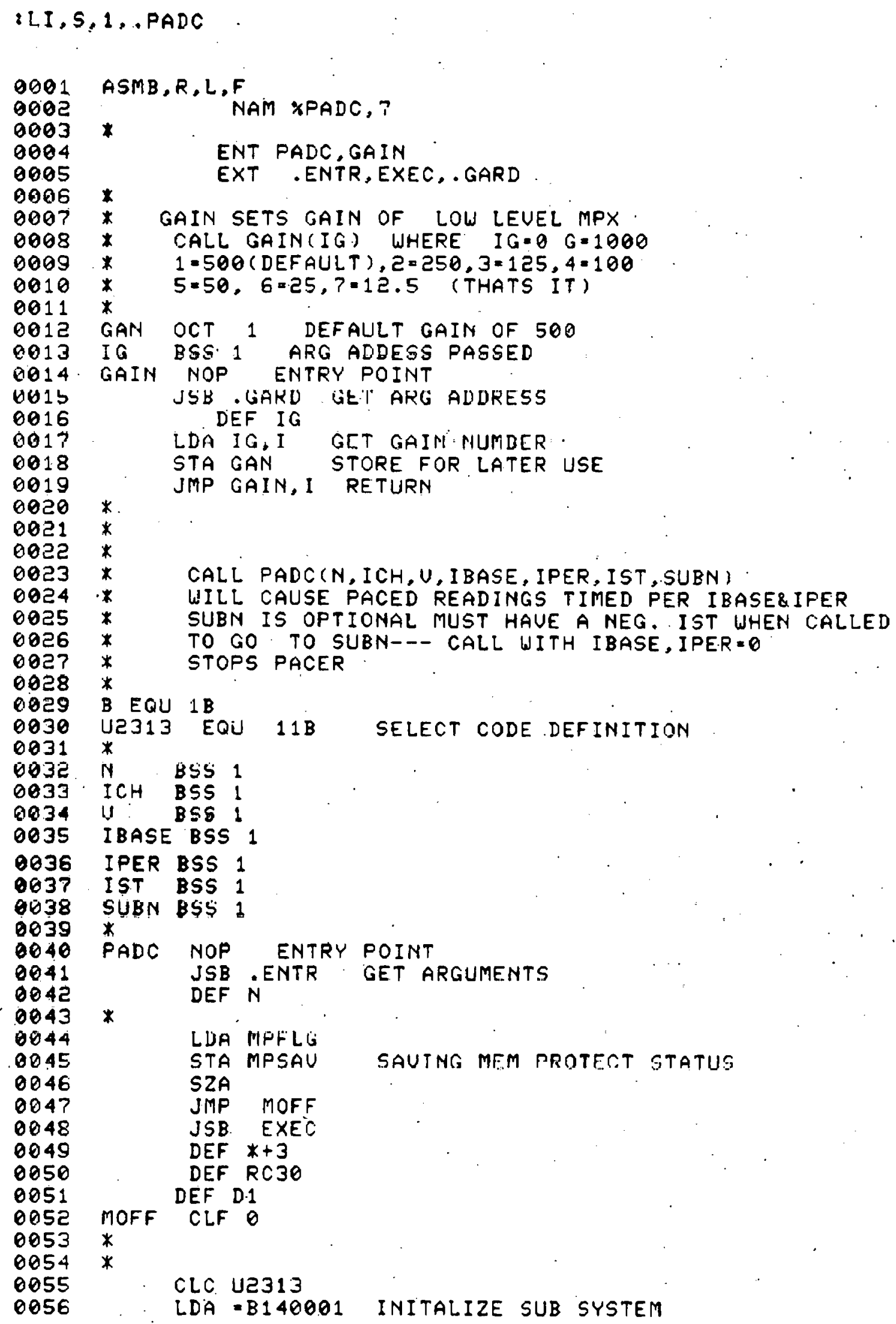




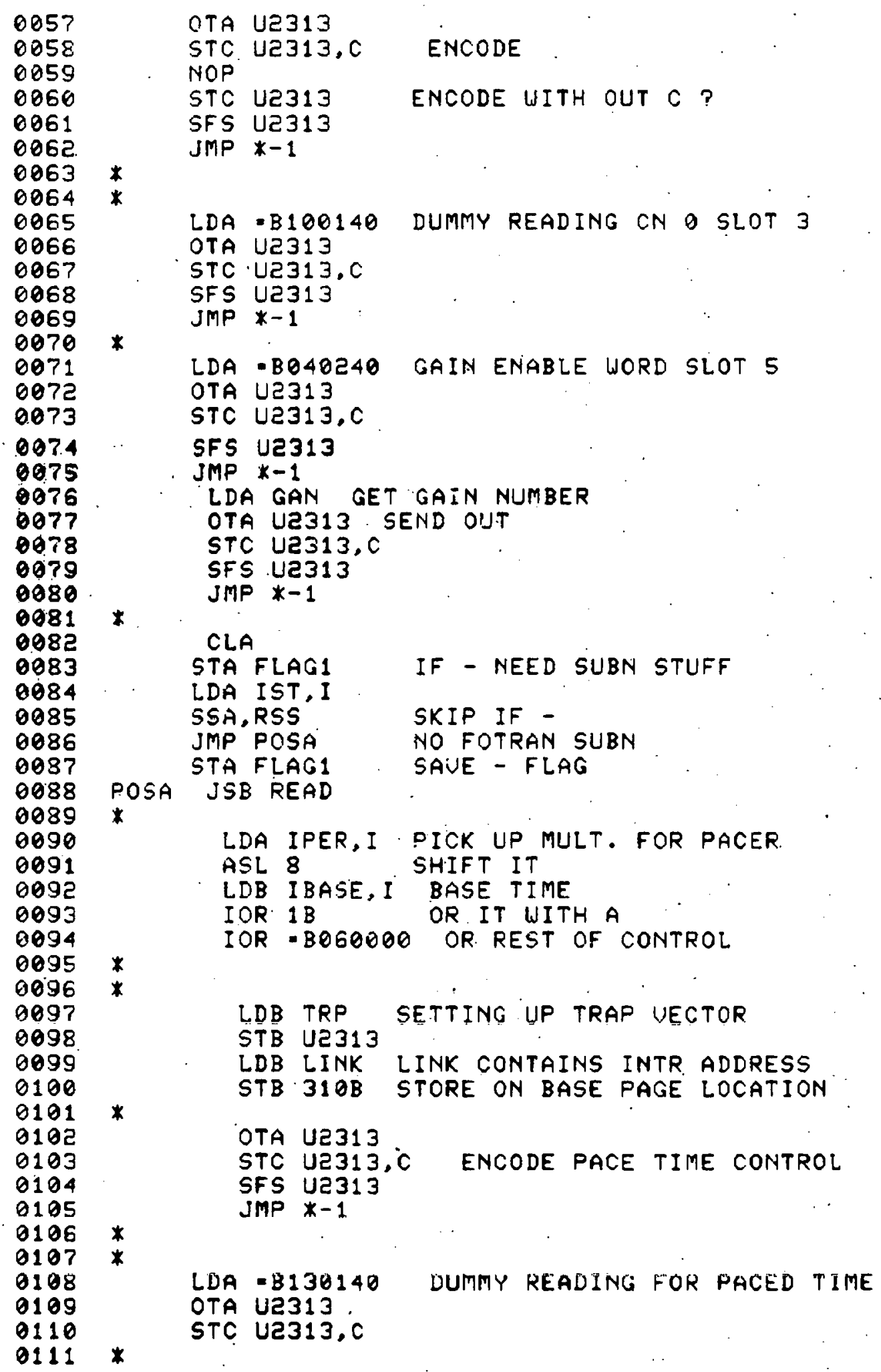




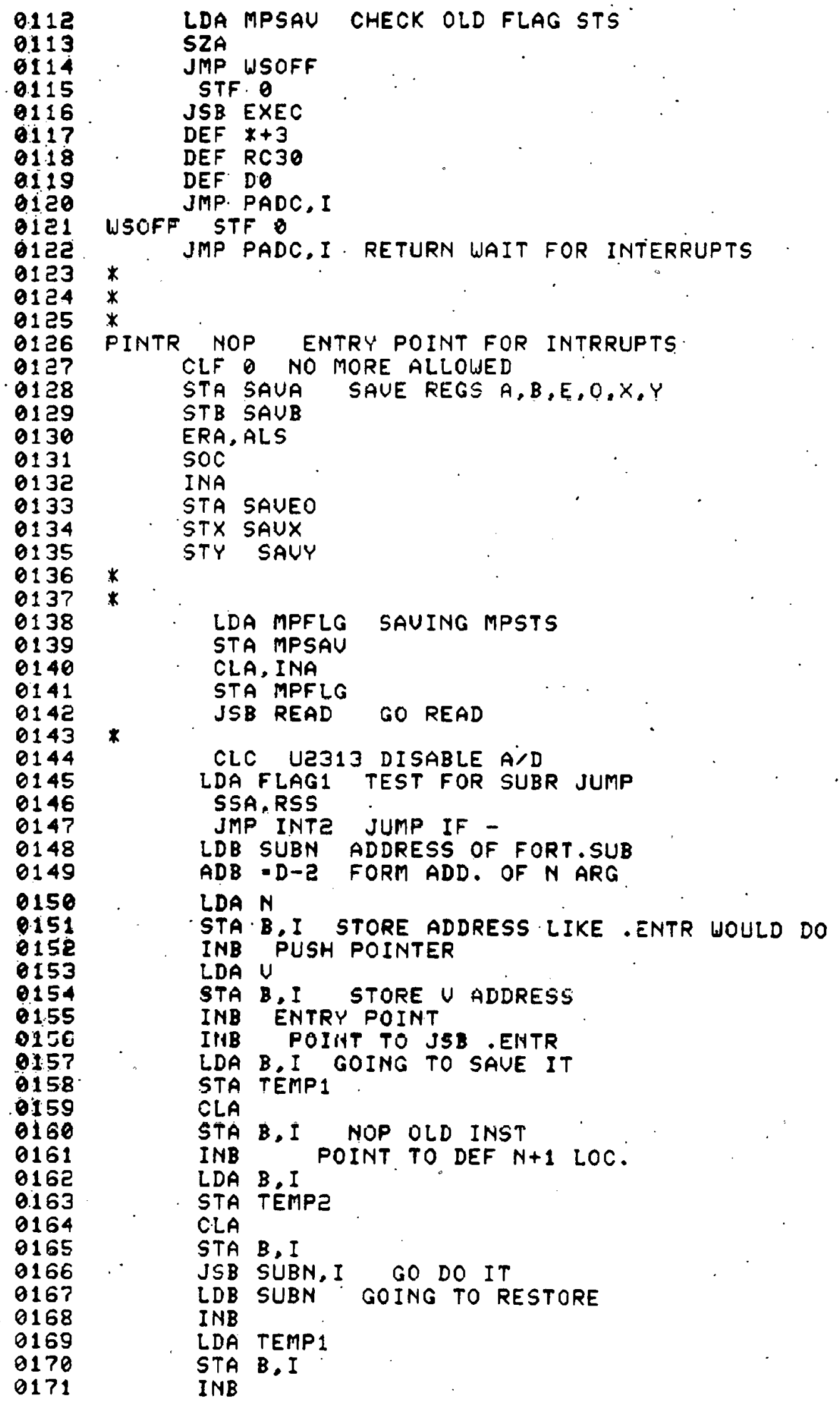




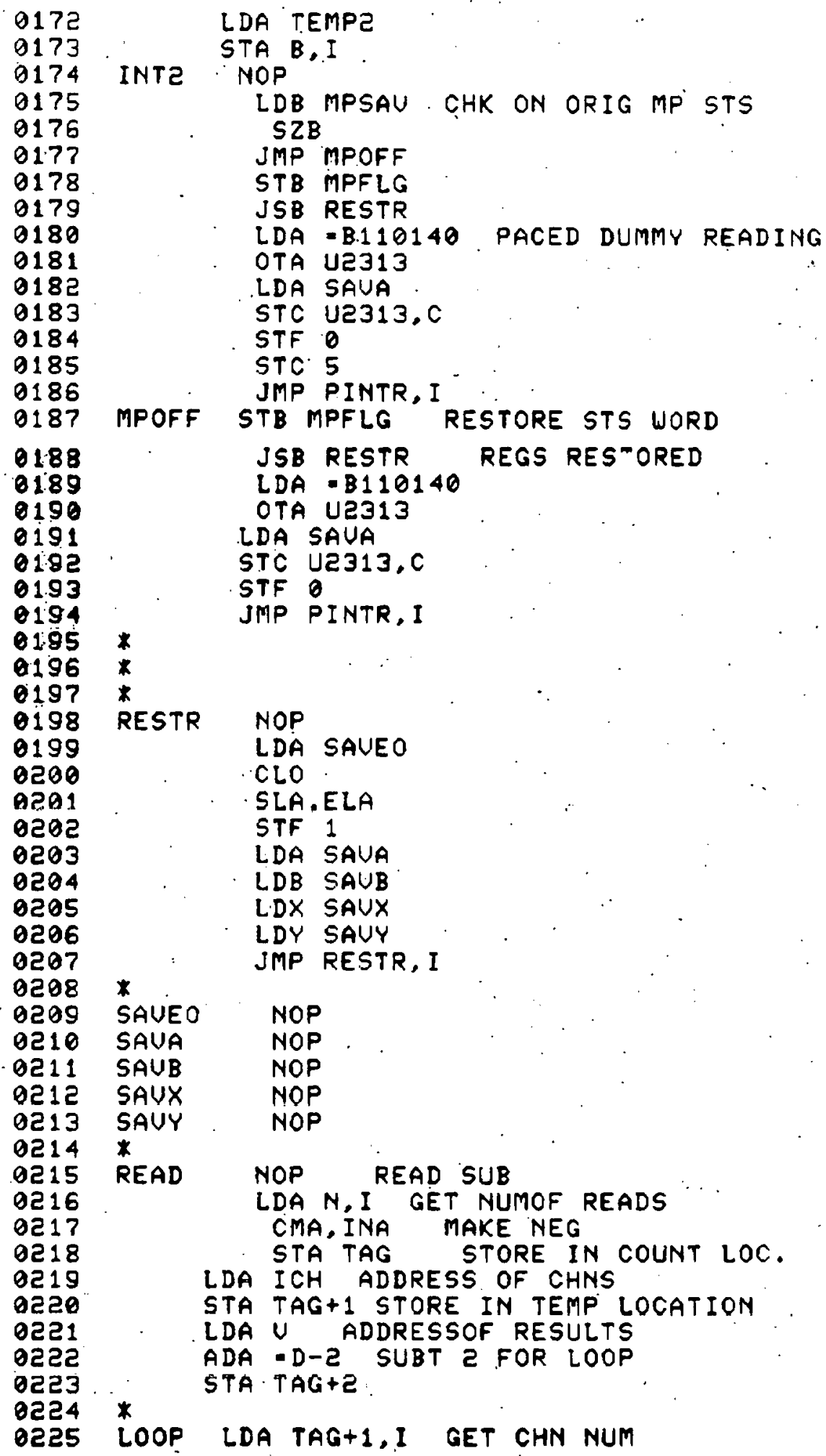




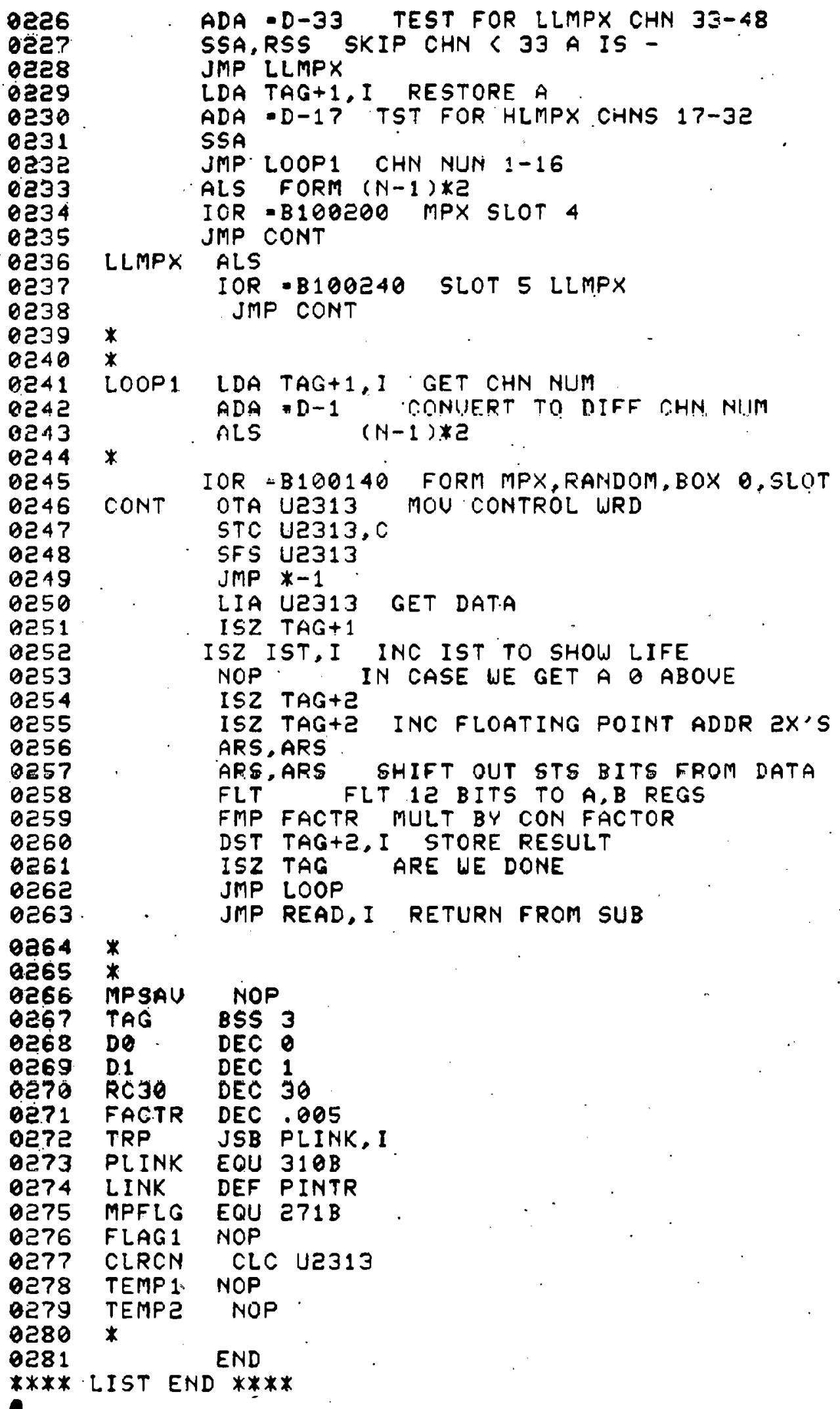

-226

बट2.?

-228

0229

0230

0231

-232

0233

0234

0235

0236

0237

0238

0239

0240

0241

Q2 42

0243

0244

0245

0246

0247

0248

0249

0250

ด251

0252

0253

0254

0255

0256

0257

0258

0259

0260

0261

0262

0263

0264

बटं65

0266.

026?

-268

0269

0570

0อ7 1

0272

0273

0274

0275

0276

$027 ?$

0278

0279

0280

0281

**** LIST END ****

ADA - D-33 TEST FOR LLMPX CHN $33-48$

SSA,RSS SKIP CHN < 33 A IS -

JMP LLMPX

LDA TAG+1, I RESTORE A

$A D A=D-1 ?$ TST FOR HLMPX CHNS 17-32

SSA

JMP LOOP1 CHN NUN 1-16

ALS FORM $(\mathrm{N}-1) \times 2$

IOR = B100200 MPX SLOT 4

JMP CONT

LLMPX

ALS

IOR - B100240 SLOT 5 LLMPX

JMP CONT

*

LOOP1 LDA TAG+1,I GET CHN NUM

ADA $D-1$ CONUERT TO DIFF SHN NIIM

ALS $\quad(N-1) * 2$

*

IOR -B100140 FORM MPX,RANAOM
CONT OTA U2313 MOU CONTROL WRD

STC U2313,C

SFS U2313

JMP $*-1$

IIA U2313 GET DATA

ISZ TAG +1

ISZ IST, I INC IST TO SHOW LIFE

NOP IN CASE WE GET A \& ABOUE

ISZ TAG+2

ISZ TAG+2 INC FLOATING POINT ADDR $2 X ' S$

ARS, ARS

ARS,ARS SHIFT OUT STS BITS FROM DATA

FLT FLT 12 BITS TO A,B REGS

FMP FACTR MULT BY CON FACTOR

DST TAG+2, I STORE RESULT

ISZ TAG ARE WE DONE

JMP LOOP

JMP READ, I RETURN FROM SUB

$*$

MPSAU NOP

TAG BSS 3

DO. DEC O

D.1 DEC 1

RCJO DEC 30

FACTR DEC .005

TRP JSB PLINK, I

PLINK EOU $310 B$

LINK DEF PINTR

MPFLG EQU $271 B$

FLAG1 NOP

CLRCN CLC U2313

TEMP 1 NOP

TEMPE NOP

* 
APPENDIX B

FORTRAN Program STRAN

(Acquires data from the PCM and provides plotting capability) 


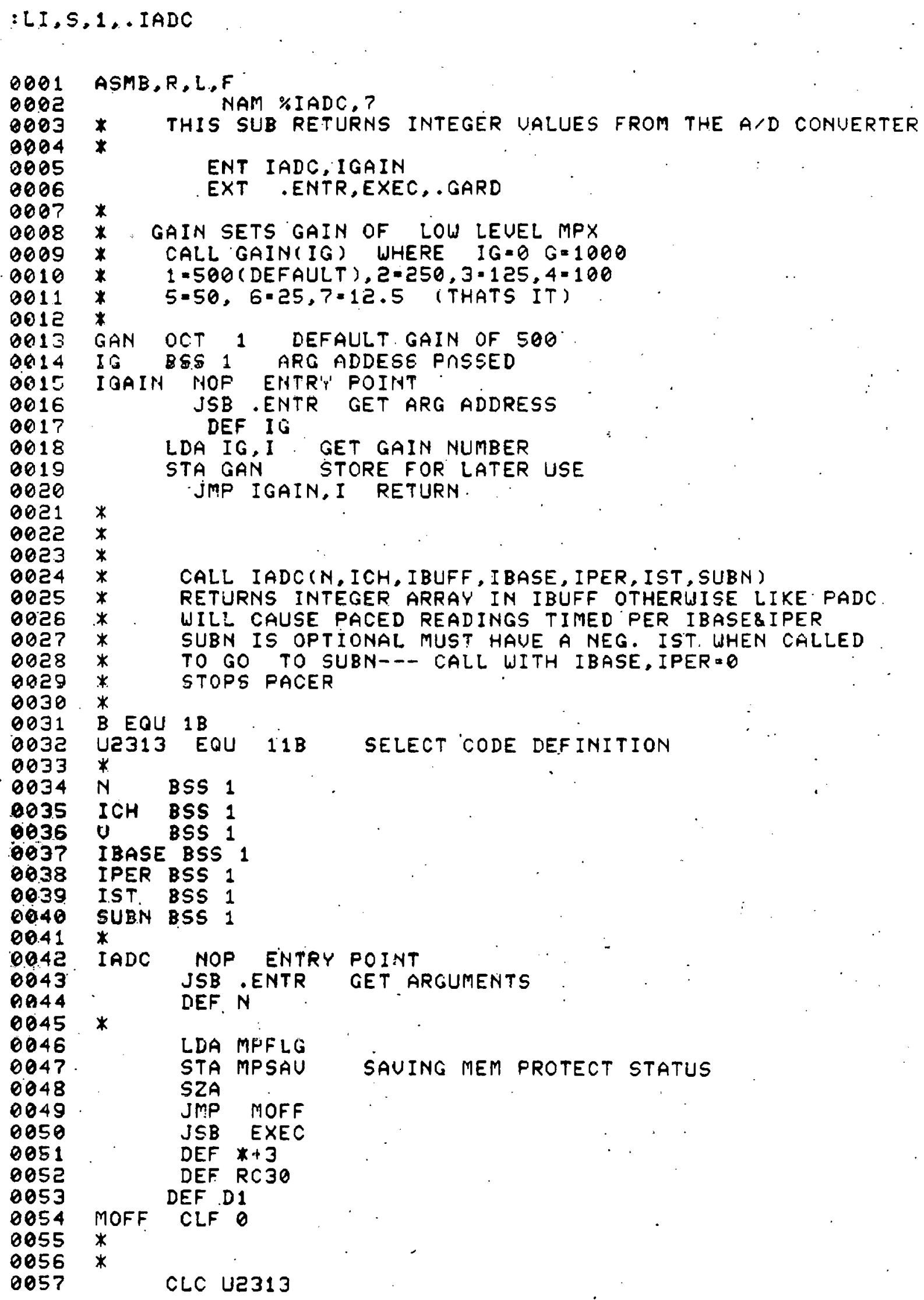




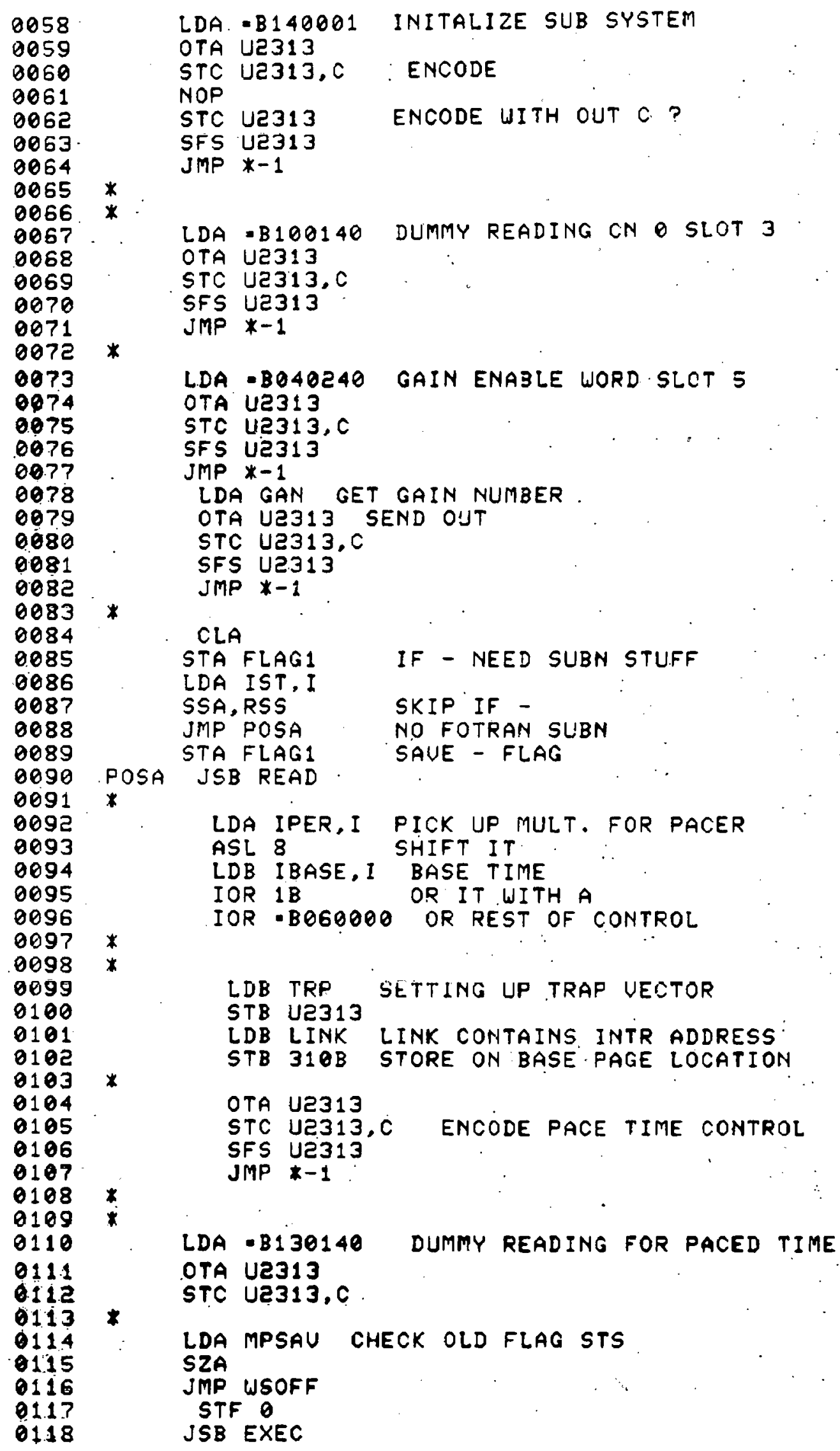

OTA U2313

STC UE313,C: ENCODE

NOP

STC UZ313 ENCODE UITH OUT C ?

SFS U2313

JMP $*-1$

*.

LDA =B100140 DUMMY READING CN O SLOT 3

OTA U2313

STC U2313,C

SFS U2313

JMP $*-1$

* L.Da -BO40240 GaIN ENable wORD. Slot 5

OTA U2313

STC U2313,C

SFS U2313

JMP $*-1$

LDA GAN GET GAIN NUMBER.

OTA UE313 SEND OUT

STC U2313,C

SFS U2313

JMP $*-1$

*

CLA

STA FLAGI IF - NEED SUBN STUFF

LDA IST, I

SSA, RSS

JMP POSA

STA FLAG1

POSA JSB READ

SKIP IF -

NO FOTRAN SLIBN

SAUE - FLAG

*

LDA IPER, I PICK UP MULT, FOR PACER

ASL 8 SHIFT IT

LDB IBASE, I BASE TIME

IOR 18 OR IT WITH A

IOR -BOGOOOO OR REST OF CONTROL

*

LDE TRP SETTING UP TRAP UECTOR STB U2313

LDB LINK LINK CONTAINS. INTR ADDRESS

STB $310 B$ STORE ON BASE. PAGE LOCATION

*

OTA U2313

STC U2313,C ENCODE PACE TIME CONTROL

SFS U2313

JMP $x-1$

$*$

LDA - B130140 DUMMY READING FOR PACED TIME

OTA U2313

STC Ue313,C

LDA MPSAU CHECK OLD FLAG STS

SZA

JMP WSOFF

STF 0

JSB EXEC 


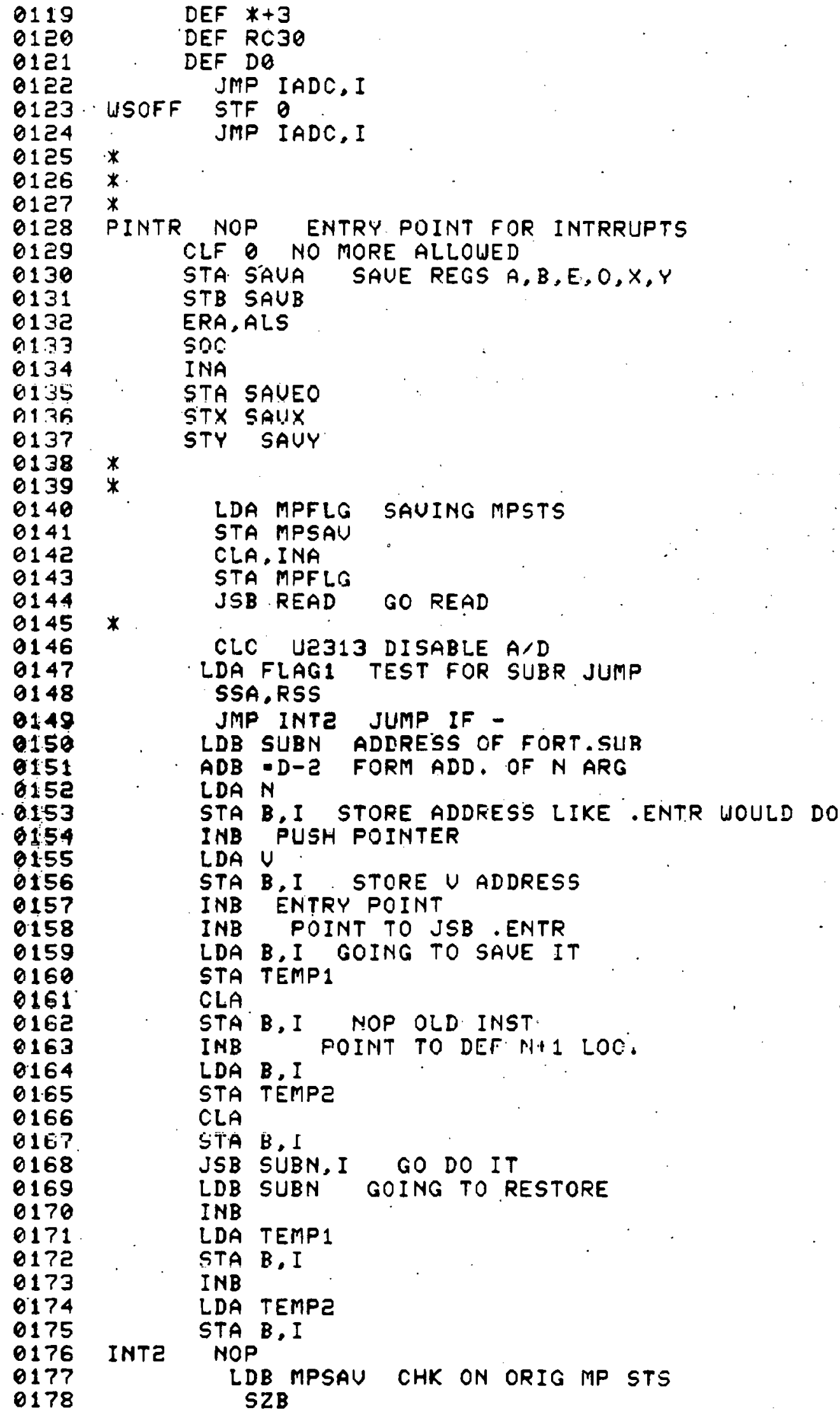




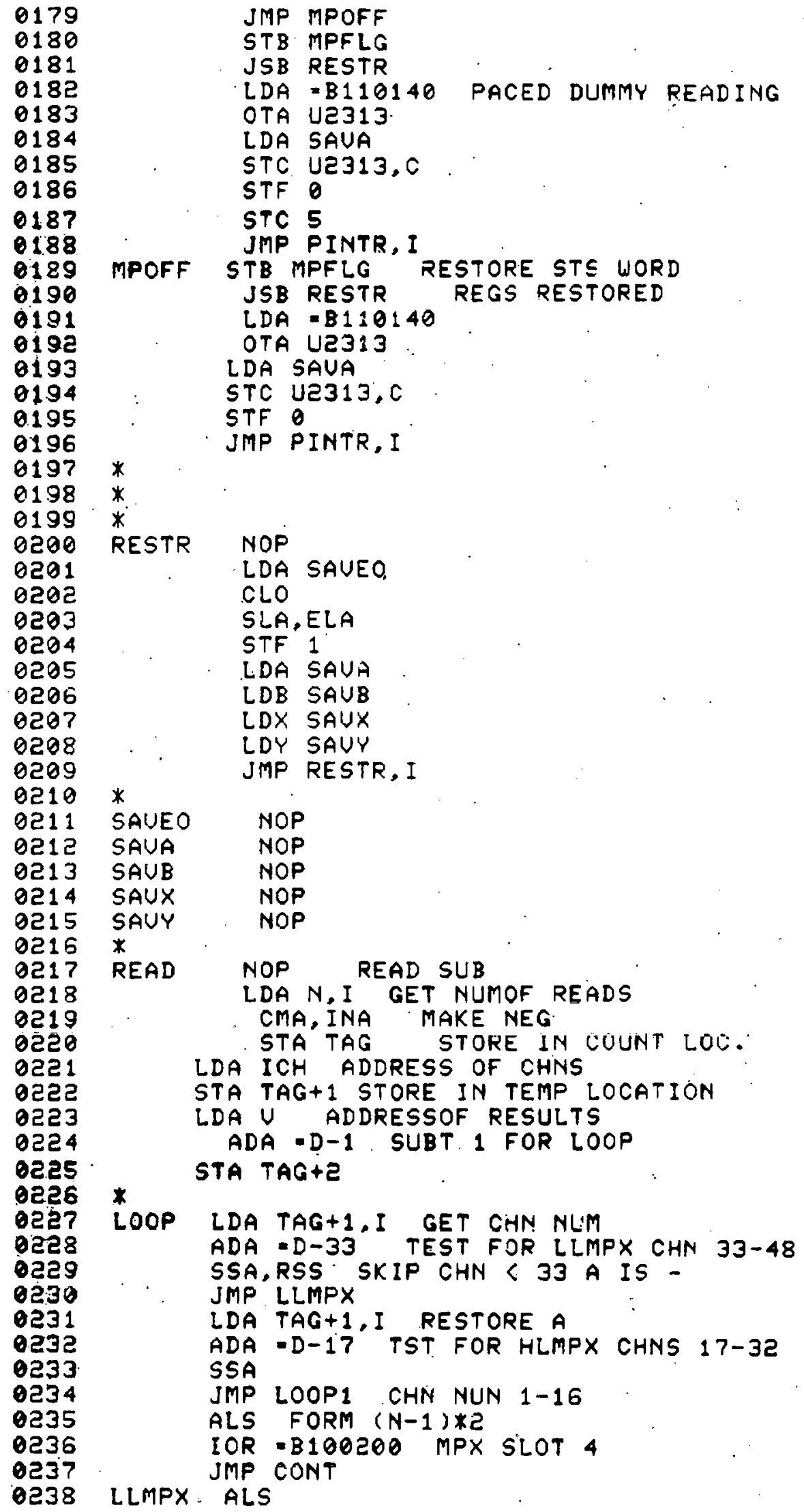




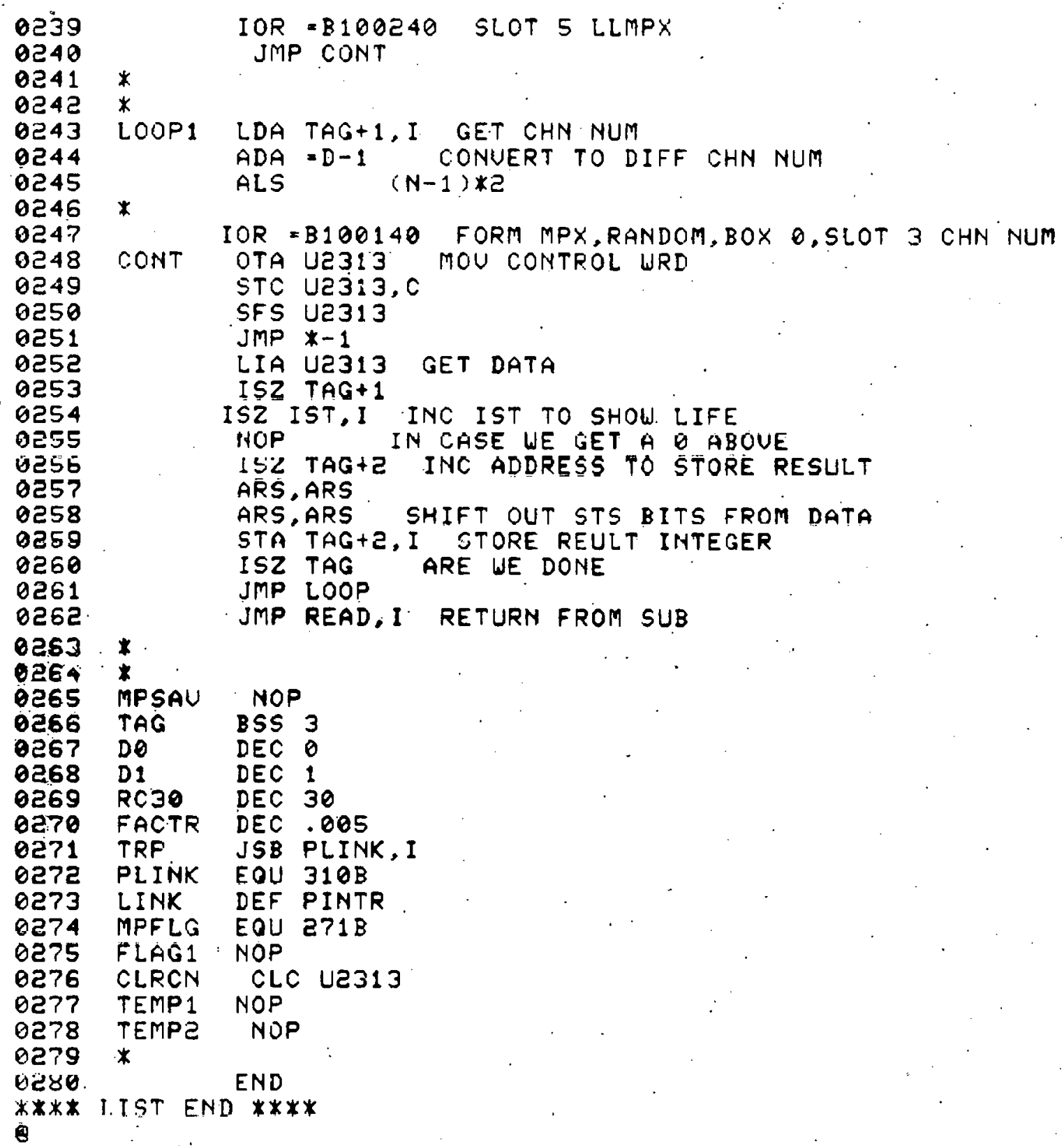


:LI,S, 1, . RELA

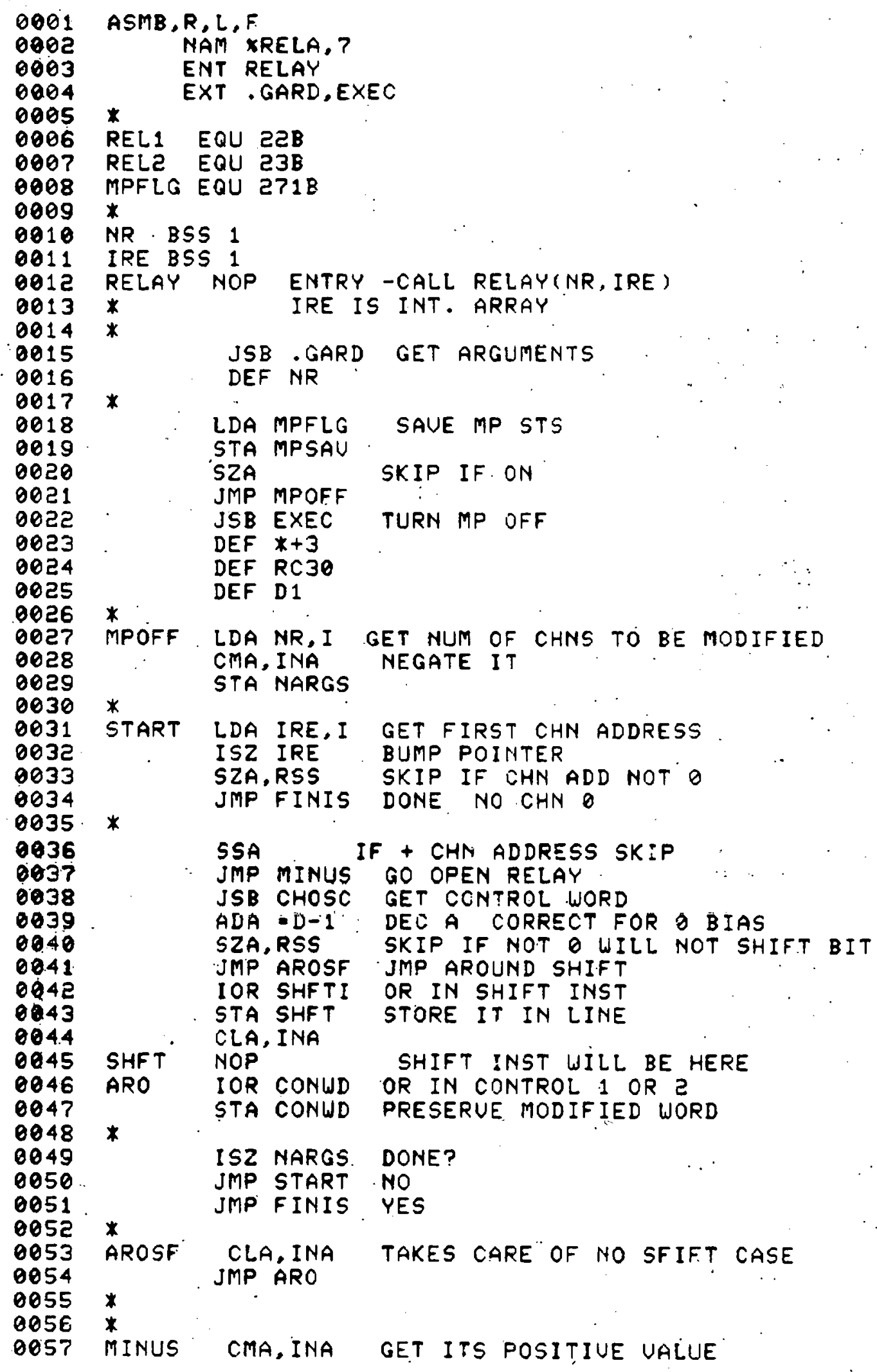




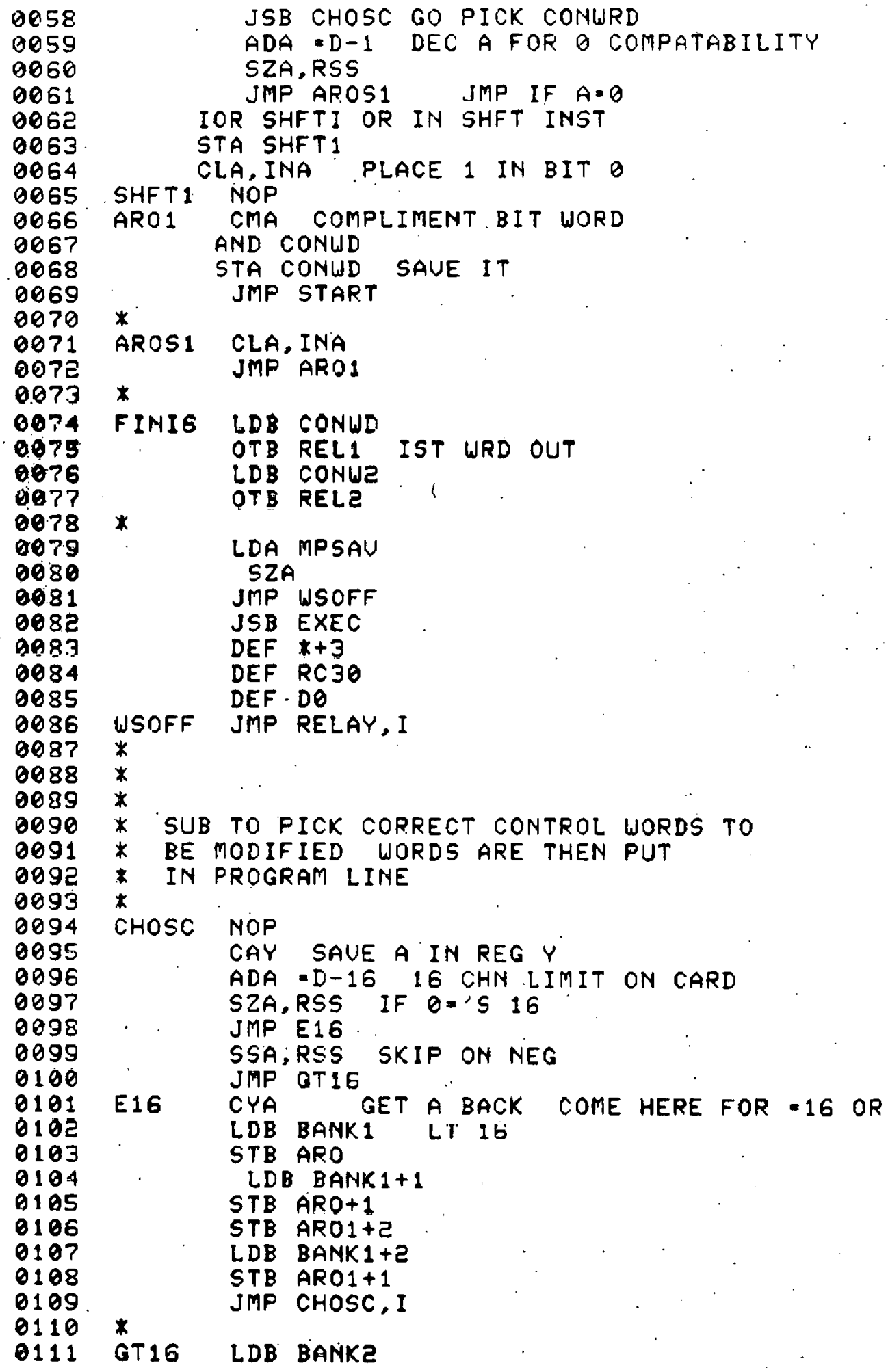




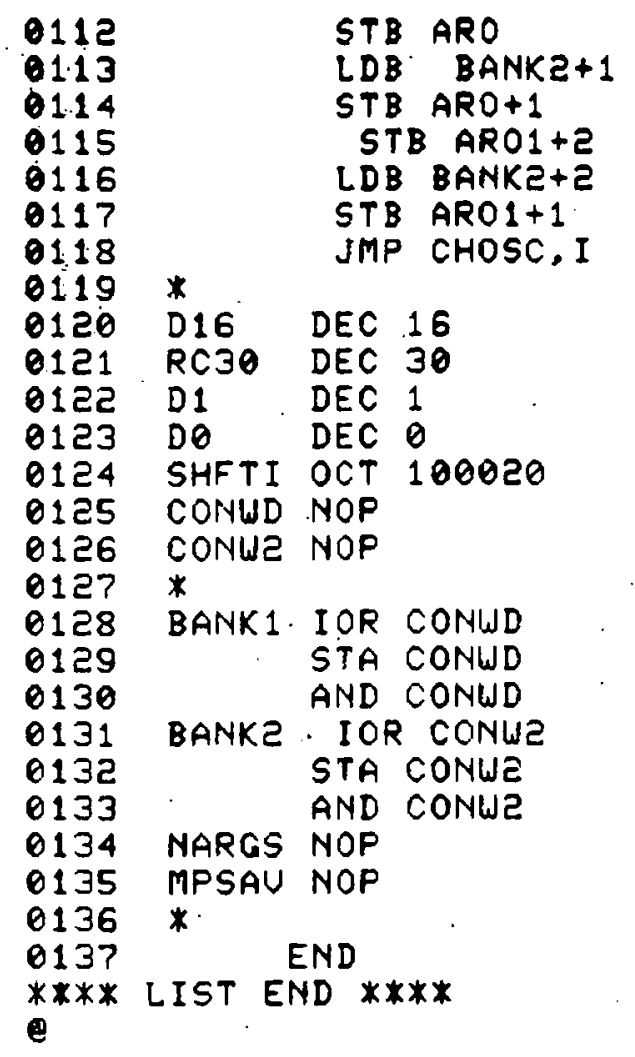


$\because L I, 5,1, . D A C$

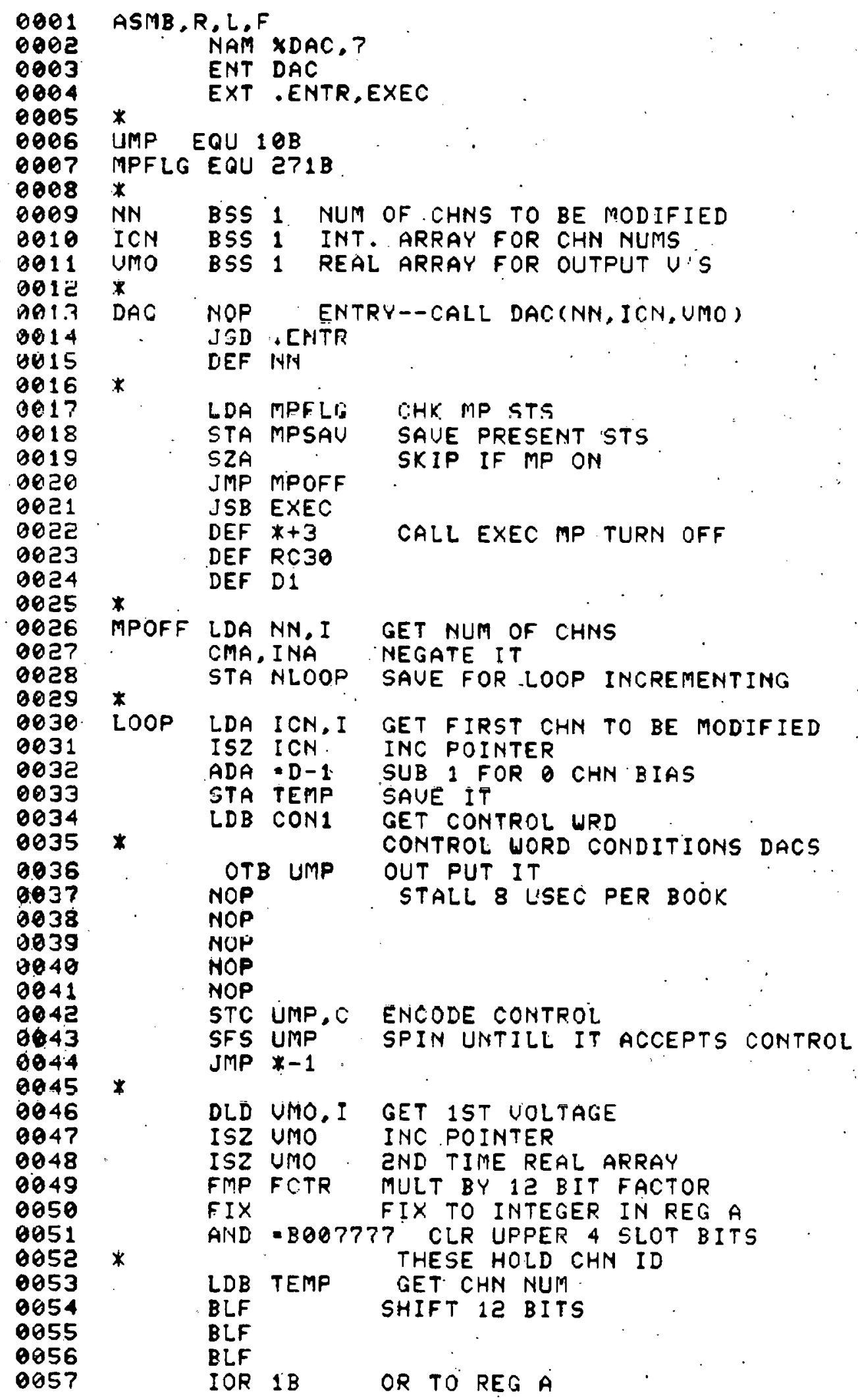




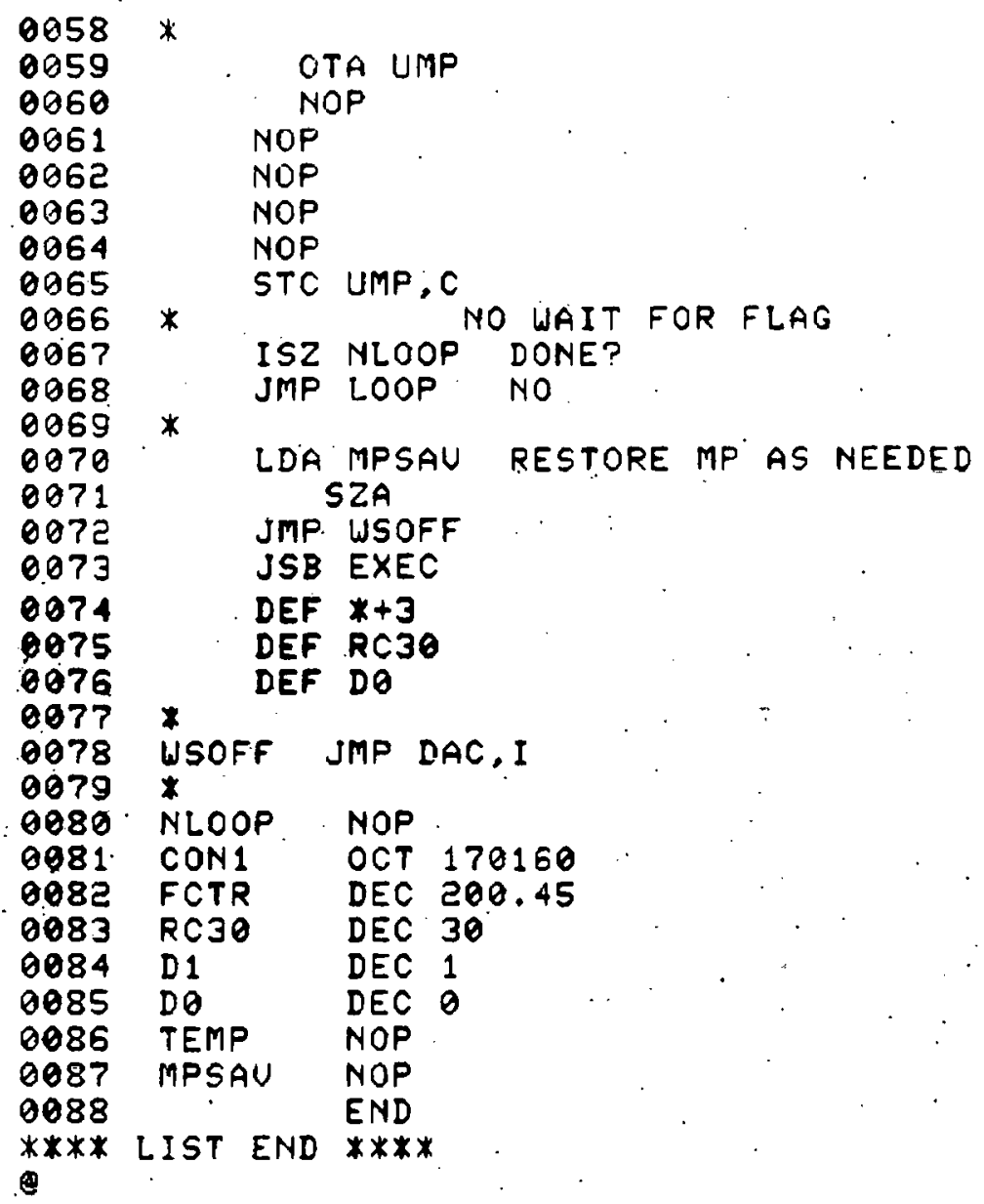


$: L I, S, 1, S$ TRAN

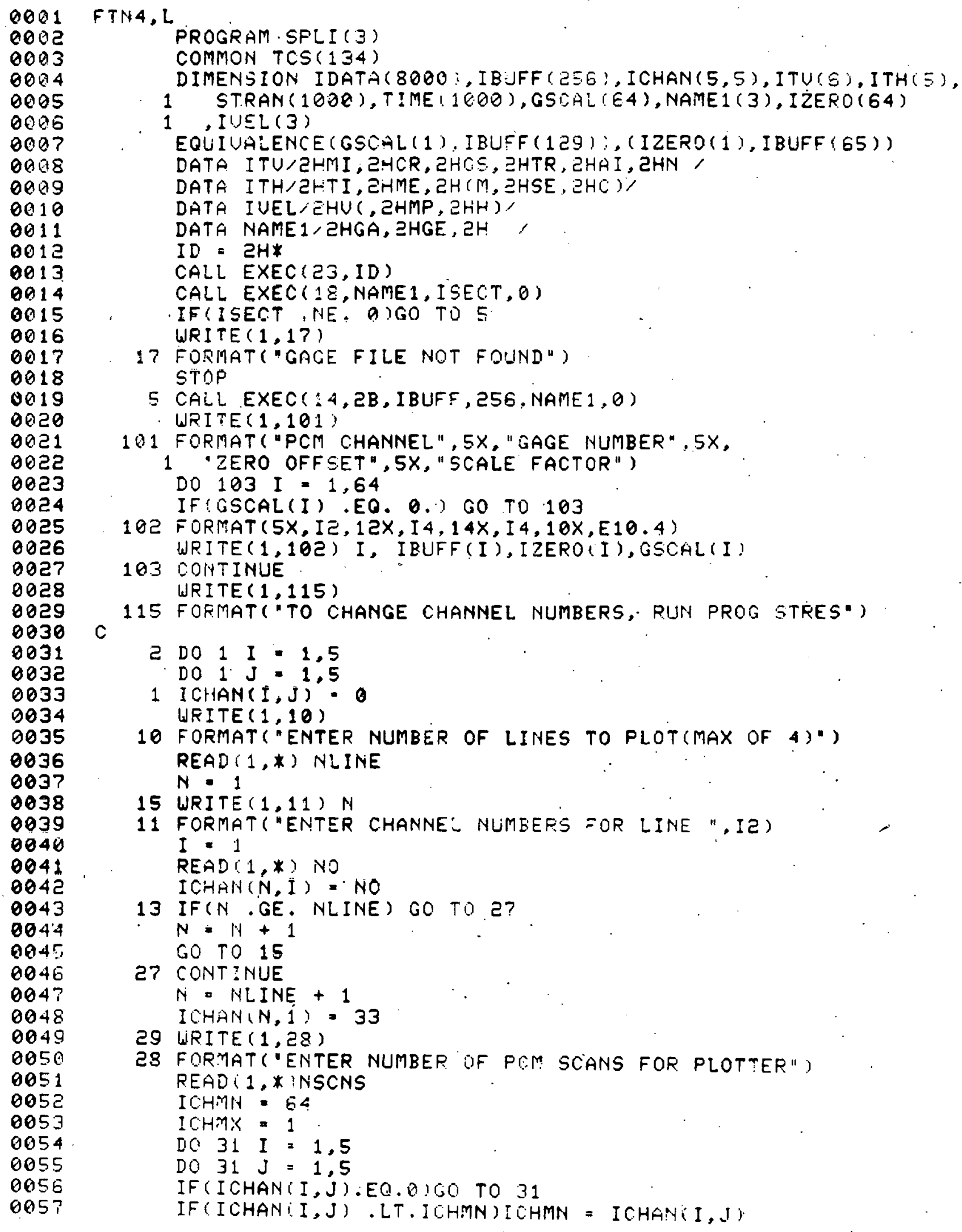


0058

0059

0060

0061

0262

0063

0064

0065

0056

0067

0058

0969

0070

0071

0072

0073

0074

0075

buTe

ต0?7

0078

0079

0080

0081

0082

0083

0084

0085

0086

008 ?

0088

0089

0090

0091

0092

0093

0094

0095

0096

009 ?

0098

0099

0100

0101

0102

0103

0104

0105

0106

0107

0108

0199

0110

0111

911.2

0113

0114

()115

0116

$011 ?$

***.

IF (ICHAN I I,J).GT. :CHMX)ICHMX = ICHAN(I,J)

31 CONTINUE

MCH $=$ ICHMX-ICHMN +1

LDATA $=$ NCHXNSCNS

$I F B C D=I C H M N$

$I L B C D=I C H M X$

CALL BNBCD(IFBCD)

CALL BNECD (ILBCD)

IF (LDATA .GT. 8000 )GOTO 29

IDATA (1) = IFBCD

IDATAC : :ILBCI

CALL EXEC (1,107B, IDATA,LDATA)

CALL PCSCL(IDATA, LDATA)

$N L=1$

$33 K=1$

IT $: 0$

DO 32 I. 1:LDATA

IU. $(I-1) / N E H$

$I C H=I-I U K N C H+I C H M N-1$

IF (ICH.NE. ICHAN (NL, K:)GO TO 32

$I T=I T+1$

IF (IT.GE. 1000 ) STOP 30

TIME:IT) * . 3*FLOAT(ICH) + FLDAT(IU)*20.

SDATA = (IDATA(I) - IZERO (ICH))

STRAN (IT: = SDATAXGSCAL(ICH)

$K=K+1$

32 CONTIN!IE

IF (ICHAN (NL,K) EEQ. B) K $=1$

IF (NL. GT. NLINE) GO TO 4 ?

IF (NL.GT. 1). GO TO 46

CALL PLOTS

$I 1=I T+1$

$I J=I T+2$

STRAN(I1) $=-1000$.

STRAN (IZ) $=500$.

IF (I2. GE. 1000). STOP 31

CALL SCALE (TIME, 6. IT I 1 )

CALL AXIS $(.5, .5$, ITH, $-10,6,0 .$, TIME (I 1$)$, TIME (I 2$))$

CALL AXIS $(.5, .5$, ITU, I2,5.,90.,STRAN(I1), STRANIIZ)!

CALL TGRID $(.5,6,5, .5,5.5)$

CALL PLOT $(.5, .5,-3)$

46 CALL LINECTIME, STRAN, IT, 1,0,NL;

$\mathrm{NL}=\mathrm{NL}+1$

GO TO 33

47 CALL FLOT $(0,3,0,-3)$

CALL AXIS $(6,0 .$, IUEL, $-6,2 ., 90,0 ., 30$.

$\operatorname{STRAN}(I 1)=0$.

STRAN (IC) $=30$.

CALL LINE (TIME, STRAN, IT , 1, 5, NL?

4.8 CALL ANMDE

CALL TINPT (M)

CALL PLOT 10.0 .0999 )

WRITE $(1,50$;

50 FORMAT ("MORE PLOTS?")

READ ( 1,117$)$ IANS

117 FORMAT (A2)

IF'IANS .EO.2HYE) SO TO 2

STOP

END

ENDS

e 
DIS'LRILUTION:

Aero Engineering Department (2)

Wichita State University

Wichita, KS. 67208

Attn: M. Snyder w. Wents

Alcoa Laboratories

Aluminum Company of America

Alcoa Center, PA 15069

Attn: D. $\dot{K}$. Ai

Serilur Sclentlic Assuniale

Dynergy Corporation

P. O. Bux 420

1269 Union Avenue

Láconia, INH 03246

Alcoa Center, PA 15069

Attn: R. B. Allen General Manager

Amcrican Wind Energy Association 54468 CR31

Bristol, IN 46507

South Dakota School of Mines and Technology

Department of Mechanical Engineering

Rapid City, SD 57701

Attn: E. E. Anderson

P. Railey.

P. O. Bux 3

Kodiak, AK 99615

Washington State University

Department of Electrical Engineering

College of Engineering

Pullman, WA y9163

Attn: F. K. Bechtel

Arizona State University

Solar Energy Collection

University Library

Tempe, A $\angle$ i 85281

Attn: M. E. Beecher

University of Oklahoma

Aero Engineering Department

Norman, OK 73069

Attn: K. Bergey

Louisiana Tech University

Department of Mechanical Engineering

Ruston, LA 71270

Attn: B. F. Blackwell
P. H. Bottelberghs

Chemical Conversion and Energy Storage

Landelijke Stuurgroep Energie Onderzoek

Dutch National Steering Group for

Eudu'by Rutivalidi

Laan van Vollenhove 3225

Zeist

The Netherlands .

McDonnell-Douglas

P. O. Bux 518

Department 241, Building 32 .

St. Louid, MO 63166

Allis. R. Drulle

R. Camerero

Faculty of Applied Science

University of Sherbrooke

Sherbrooke, Quebec

Canara J1K. 2R.1

University of Hawaii

Wind Engineering Research Digest

Spalding Hall 357

Hololulu, HI 96822

Attn: A. N. L. Chiu

US Department of Agriculture

Agricultural Research Service

Southwest Great Plains Research Center

Bushland, IX 79012

Attn: R. IJ. Clark

Lockheed California Co.

Box 551-63A1

Burbank, CA 91520

Attn: U. A. Coty

Alcoa Mill Producls

Alcoa Center, HA 1 búby

Attn: A. G. Craig

US Department of Energy (3)

Albuyuerque Operations ofrice

P. O. . Box 5400

Albuquerque, NM 87185

Attn: D. K. Nowlin

W. P. Grace

D. W. King

US Department of Tnergy; Headquartere Washington, DC 20545

Attn: L. V. Divone, Chief Wind Energy Conversion Branch

D. D. Teague Wind Energy Conversion Branch 
DIST RIBUTION： (cont)

Prof. A. V. da Rosa

C. P. 1.170 (UNICAMP)

13. 100 Campinas, S. P.

Brazil

Southern Illinois University

School of Engineering

Carbondale, IL 62901

Attn: C. W. Dodd

Hamilton Standard

1730 NASA Boulevard

Room 207

Houston, TX 77058

Attn: D. P. Dougan

J. B. Dragt

Physics Department

Westerduinweg 3 Patten (nh)

The Netherlands

Electric Power Research Institute

3412 Hillview Avenue

Palo Alto, CA 94304

Attn: P. Bos

Research Dynamics Associates

P. O. Box 211

Menlo. Park, CA 94025

Attn: W. J. Ewing. President

J. Fischer

F. L. Smidth \& Company A/S

Vigerslevalle 77

2500 Valby, Denmark

Environmental Protection Specialist

Department of Environmental Resources

736 West Fonrth Street.

Williamsport, PA 17701

Attn: R. E. Fisher

University of Colorado

Department of Aerospace Engineering Sciences

Boulder, CO 80309

Attn: J. D. Fock, Jr.

Aerophysics Company

3500 Connecticut Avenue NW

Washington, DC 20008

Attn: W. F. Foshag

Albert Fritzsche

Dornier System $\mathrm{GmbH}$

Pustfach 1360

7990 Friedrichshafen

West Germany
Tyler \& Reynolds \& Craig

One Boston Place

Boston, MA

Attn: W. W. Garth, IV

Amarillo College

Amarillo, TX 79100

Attn: E. Gilmore

TRW Energy Systems.

7600 Colshire Drive

Mclean, VA 22101

Attn: R. Gorman

Massachusetts Institute of Technology

77 Massachusetts Avenue

Cambridge, MA 02139

Attn: N. D. Ham

DOE/DSE

20 Massachusetts Avenue

Washington, DC 20545

Attn: S. Hansen

SERI

1536 Cole Blvd.

Golden, CO 80401

Attn: D. IM. Hardy

Massachusetts Institute of Technology

Aero/Astro Department

Cambridge, MA 02139

Attn: W. L. Harris

Rocky Flats Flant (2)

P. O. Box 464

Golden, CO 80401

Attn:' T. Healy

Allegany Ballistics Laboratory:

Hercules, Inc.

P. O. Box 210

Cumberland, MD 21502

Attn: P. W. Hill

Aluminum Company of America (2)

Alcoa Laboratories

Alcoa Center, PA 15069

Attn: J. T. Huang

J. R. Jombock

Sven Hugoss on

Box 21048

S. 10031 Stockhold 21

Sweden

O. Igra

Department of Mechanical Ingineering Ben-Gurion University of the Negev

Beer-Sheva, Is rael 
JBF Scientific Corporation

2 Jewel Drive

Wilmington, MA 01887

Attn: E. E. Johanson

Slanford University

Department of Mechanical Engineering

Stanford, CA 94305

Attn: J. P. Johnston

Kaman Aerospace Corporation

Old Winds or Road

Blonmfield, C.T O60ก?

Attni W. Batosol

Michigan State University

Division of Engineering Research

East Lansing, MI 48824

Attn: O. Krauss

Shell, Dil. Company

Energy Economics and Forecasting

Planning and Economics

P. O. Box 2463

Houston, TX 77001

Attn: S. M. Lambert, Manager.

Iniversity of California

Lawrence Livermore Laboratory

P. O. Box 808 L' -340

Livermore, CA 94550

Attn: D. W. Dorn

Public Service Company of New Mexico P. O. Box 2267

Albuque rque, NM 8\%103

Attn: M. Lechner

Reynolds Metals Cómparsy

Mill Products Division

bbul West Broad Street

Richmond, VA 23261

Attn: G. E. Lennox

Industry Director

State Finergy rommission

Research and Development Division

1111 Howe Avenue

Sacramento, CA 95825

Attn: J. Lerner

Ưs Departrrent of Agricullure

Agriculture Research Center

Building 303

Beltsville, MD 20705

Attn: L. Liljdahl
Aeroenvironment, inc.

660 South Arroyo Parkway

Pasadena, CA 91105

Attn: P. B. S. Lissaman

O. Ljungstrom

Swedish Board for Technology Development

FACK

S-100 72 Stockholm 43, Sweden

Los Alamos Scientific Laboratories

P. Q. Bux 1663

Tos Alamos. NM 87544

$\Delta+\dot{t}_{n}$.T. $\mathrm{n}$. Ralrnmh $\mathrm{s}-\overline{\mathrm{T}} \mathrm{n}-\mathrm{T}$

$$
\text { Library }
$$

L. H. J. Maile

48 York Mílls Rd.

Willowdale, Ontario

Canada M2 P 1B4

Dardalen Associates

15110 Frederick Road

Woodbine, MD 21797

Attn: F. Matanzo

Kaman Sciences Corporation

P. O. Box 7463

Colorado Springs, CO 80933

Attn: J. Meiggs

Colorado State University

Department of Civil Engineering

Fort Colilins, CO 80521

Attn: R. N. Meroney

Department of Economic Planning and Development Barrett Building

Clieyenine, WY 82002

Attn: G. N. Monsson

D. Myrick

i05 Skipper Avenue

Ft. Walton Beach, $\mathrm{FL}^{\mathrm{L}} 32548$

National Aeronautics and Space Administration

Langley Research Center

Hampton, VA 23665

Attn: R. Muraca, MS317

National Aeronautics and Space Administration (3)

Lewis Research Center

2100 Brookpark Road

Cleveland, $\mathrm{OH} 44135$

Attn: J. Savino, MS509-201

R. L. Thomas

W. Robbins 
DIST RIBUTION: (cont)

West Texas State University Department of Physics

P. O. Box 248

Canyon, TX 79016

Attn: V. Nelson

Oklahoma State University

(2)

Stillwater, OK 76074

Attr: W. L. Hughes EE Department

D. K. McLaughlin ME Department

Oregon State University

Corvallis, OR 97331

Attn: R. Wilson ME Department

R. W. Thresher ME Department

Dow Chemical USA

Research Center 2800 Mitchell Drïve Walnut Creek, CA 91598

Attn: H. H. Paálman

Helion

P. O. Bư 4301

Sylmar; CA 91342

Attn: J. Park

Northwestern University

Department of Civil Engineering

Evanston, IL 60201

Attn: R. A. Parmelee.

B. Maribo Pedersen

Department of Fluid Mechanics

Building 404, DTH

2800 Lyngby

Denmark

A. Robb

Memorial University of Newfoundland

Faculty of Engineering and Applied Sciences

St. John's Newfoundland

Canada A1C 5S7

T. P. Rünero

P. O. Box 2806

Las Vegas, NM 87701

Stanford Electronic Laboratories

Radio Science Laboratory

Stanford, CA 94305

Att.n: A. V. da Rosa
Rocket and Space Division

Bristol Aerospace Ltd.

P. O. Box 874

Winnipeg, Manitoba

Canada R3C 2S4

Attn: H. Sevier

P. N. Shankar

Aerodynamics Division

National Aeronautical Laboratory

Bangalore 560017

India

Cornell University

Sibley School of Mechanical and

Aerospace Engineering

Ithaca, NY 14853

Attn: D. G. Shepherd.

Colorado State University

Mechanical Engineering Department

Ft. Collins, CO 80521

Attn: F. Smith, Dept. Head

Iowa State University

Agricultural Engineering

Room 213

Ames, IA 50010

Attn: L. H. Soderholm

Southwest Research Institute (2)

P. O. Drawer 28501

San Antonio, TX 78284

Attn: W. L. Donaldson, Senior Vice President R. K. Swanson

Morey/Stjernholm and Associates

1050 Magnolia Street

Colorado Springs, CO 809.07

Attn: D. T. St.jernholm, P. F. Mechanical Design Engineer

Iowa State University

Climatology and Meteorology

312 Curtiss $\cdot$ Hall

Ames, IA 50010

Attn: E. S. Takle

R. J. Templin (3)

Low Speed Aerodynamics Section

NRC-National Aeronautical Establishment

Ottawa 7, Ontario

Canada K1A OR6

Texas Tech University

P. O. Box 4289

Lubbock, TX 79409

Attn: IS. C. Mehlä, CE Department

J. Strickland, ME Department

J. Lawrence, ME Department 
DISTRIBUTION: (cont) :

Atari, Inc.

155 IMoffett Park Drive

Sunnyvale, CA 94086

Attn: F. Thompson

United Engineers and Constructors, Inc. Advanced Fingineering Department 30 South 17 th Street

Philadelphia, PA 19101

Attn: A. J. Karalis

United Nations Environment Program

485 Lexirigton Avenut

New York, NY 10017

Attn: I. H. Uemeni.

University of New Mexico (2)

Albuyuerque, NM 87106

Attn: K. T. Feldman Energy Research Center

v. Sloglund ME Department

Illinois Institute of Technology Department of Electrical Engineering 3300 South Federal

Chicago, IL 60616

Attn: A. G. Vacroux

Alcoa Allied Products

Alcoa Center. PA 15069

Attn: P. N. Vosburgh, Development Manager

O. de Vries

National Aerospace Laboratory

Anthony Fokkerweg 2 .

Amsterdam 1017

The Netherlands

West Virginia University

Department of Aero Ingineering

1062 Kountz Avenue

Morgantown, WV 26505

Attn: R. Walters

Bonneville Power Administration

P. ก. Rox 3621

Portland, OR 97225

Attn: E. J. Warchol

Tulane University

Department of Mechanical Engineering

New Orlcans, LA 70018

Attn: R. G. Watts

University of Alaska

Geophysical Institute

Fairbanks, AK 99701

Attn: T. Wentink, Jr.
West Texas State University

Government Depository Library

Number 613

Canyon, TX 79015

C. Wood

Dominion Aluminum Fabricating Ltd.

$3570^{\circ}$ Hawkestone Road

Mississauga, Ontario

Canada L5C 2 V8

1000

1300

1260

1280

12,84

1300

1320

1324

1324

1330

1331

1332

1333

1333

1334

1335

1336

1521

1521

3161

3161

5333

5333

5700

5710

5715

5715

5715

5715

5715

5722

8266

3141

3151

G. A. Fowler

L. D. Smith

K. J. Touryan

T. B, Lane

R. $\therefore$ Renter. ITr.

D. B. Shuster

M. M. Newsom

L. C. Rightley

L. V. Feltz

R. C. Maydew

H. R. Vaughn

C. W. Peterson

S. McAlees, Jr.

R. E. Sheldahl

D. D. McBride

W. R. Barton

J. R. Cole

J. L. Mortlcy

R. N. Tomlinson

J. E. Milchell (50)

P. S. Wilson

R. E. Akins

J; W. Reed

J. H. Scott

G. E. Brandvold

R. H. Braasch (200)

J. D. Burkhardt

E. G. Kadlec

W. N. Sullivan

M. H. Worstell

K. Walley

E. A. Aas

'L. L. Werner (5)

W. L. Garner (3) .

for DOE/TIC (Unlimited Release) 